\title{
Dynamical downscaling of CMIP5 global circulation models over CORDEX-Africa with COSMO-CLM: evaluation over the present climate and analysis of the added value
}

\author{
Alessandro Dosio • Hans-Jürgen Panitz • \\ Martina Schubert-Frisius • Daniel Lüthi
}

Received: 10 January 2014 / Accepted: 12 July 2014 / Published online: 29 July 2014

(C) The Author(s) 2014. This article is published with open access at Springerlink.com

\begin{abstract}
In this work we present the results of the application of the consortium for small-scale modeling (COSMO) regional climate model (COSMO-CLM, hereafter, CCLM) over Africa in the context of the coordinated regional climate downscaling experiment. An ensemble of climate change projections has been created by downscaling the simulations of four global climate models (GCM), namely: MPI-ESM-LR, HadGEM2-ES, CNRM-CM5, and EC-Earth. Here we compare the results of CCLM to those of the driving GCMs over the present climate, in order to investigate whether RCMs are effectively able to add value, at regional scale, to the performances of GCMs. It is found that, in general, the geographical distribution of mean sea level pressure, surface temperature and seasonal precipitation is strongly affected by the boundary conditions (i.e. driving GCMs), and seasonal statistics are not always improved by the downscaling. However, CCLM is generally able to better represent the annual cycle of precipitation, in particular over Southern Africa and the West Africa monsoon (WAM) area. By performing a singular spectrum analysis it is found that CCLM is able to reproduce
\end{abstract}

\footnotetext{
A. Dosio $(\bowtie)$

Institute for Environment and Sustainability, European

Commission Joint Research Centre, via E.Fermi 2749,

21027 Ispra, VA, Italy

e-mail: alessandro.dosio@jrc.ec.europa.eu

H.-J. Panitz

Karlsruher Institut für Technologie, Karlsruhe, Germany

M. Schubert-Frisius

Helmholtz-Zentrum Geesthacht, Geesthacht, Germany

D. Lüthi

Swiss Federal Institute of Technology (ETH), Zurich,

Switzerland
}

satisfactorily the annual and sub-annual principal components of the precipitation time series over the Guinea Gulf, whereas the GCMs are in general not able to simulate the bimodal distribution due to the passage of the WAM and show a unimodal precipitation annual cycle. Furthermore, it is shown that CCLM is able to better reproduce the probability distribution function of precipitation and some impact-relevant indices such as the number of consecutive wet and dry days, and the frequency of heavy rain events.

Keywords COSMO-CLM regional climate model . CORDEX-Africa · CMIP5 GCMs · Added value

\section{Introduction}

Africa is one of the regions most vulnerable to weather and climate variability (IPCC 2007). Due to its low adaptive capacity, projected climate change may lead to severe impacts on many vital sectors such as agriculture, water management, and health. For these reasons, and the general lack of climate projections based on Regional Climate Downscaling tools, Africa was selected as the first target region for the World Climate Research Programme CORDEX (Coordinated Regional climate Downscaling Experiment) (Giorgi et al. 2009). CORDEX aims to foster international collaboration in order to generate an ensemble of high-resolution historical and future climate projections at regional scale, by downscaling different Global Climate Models (GCMs) participating in the Coupled Model Intercomparison Project Phase 5 (CMIP5) (Taylor et al. 2012).

It is very challenging for climate models to replicate the multitude of physical processes and the complexity of their feedbacks, which span multiple temporal and spatial scales, over such a large and heterogeneous continent. In 
fact, despite GCMs have demonstrated the ability to generally replicate the precipitation trend over the second half of the twentieth century, they may present significant deficiencies in simulating the African climate, especially complex systems like the West Africa Monsoon (WAM), which is driven by the interaction of atmosphere, ocean, and landsurface, initiated by differential heating of the ocean and land surface (e.g. Steiner et al. 2009), and also strongly related to mid-tropospheric circulation such as the African Easterly Jet (AEJ) (Cook 1999).

By using the information provided by GCMs as lateral boundary condition, limited area, high resolution climate models (Regional Climate Models-RCMs) are used to provide climate information at spatial scales much finer than the GCMs' grid (usually of the order of hundred of $\mathrm{km}$ ). By better representing the topographical details, coastlines, and land-surface heterogeneities, RCMs allows the reproduction of small-scale processes and details that are most useful for instance for impact assessment and adaptation policies (e.g. Wang et al. 2004; Paeth and Mannig 2012; Lee and Hong 2013).

Many studies in the past have investigated the ability of RCMs to reproduce the general features of the African climate, especially over Southern and West-Africa (e.g. Jenkins et al. 2005; Afiesimama et al. 2006; Abiodun et al. 2008), where they generally improved the climate simulations by GCMs but also shared similar biases (IPCC 2007). A comprehensive effort has been subsequently undertaken in data collecting and modeling activities focused primarily on the West Africa region, including the West African Monsoon Modelling and Evaluation (WAMME) initiative (Druyan et al. 2010; Xue et al. 2010), the African Multidisciplinary Monsoon Analysis (AMMA) (Redelsperger et al. 2006; Ruti et al. 2011), and the Ensembles-based prediction of Climate Changes and Their Impacts (ENSEMBLES) (Paeth et al. 2011).

More recently, in the framework of the CORDEX initiative, several RCMs driven by 'observed' lateral boundary conditions (ERA-Interim), have been evaluated (Nikulin et al. 2012; Endris et al. 2013; Kalognomou et al. 2013; Kim et al. 2013; Gbobaniyi et al. 2013; Panitz et al. 2014) in order to asses the 'structural bias' of the models (Laprise et al. 2013). It is shown that in general RCMs simulate the precipitation seasonal mean and annual cycle quite accurately, although individual models can exhibit significant biases in some subregions and seasons.

When RCMs are driven by GCMs, however, the downscaled climate may present even larger biases, as the ones inherited through the lateral boundary conditions are added to those introduced by the RCM by means, for instance, of model errors and parameterizations (e.g. Dosio and Paruolo 2011; Hong and Kanamitsu 2014). As downscaling is not able to improve the simulation skills of large-scale fields over those simulated by the GCMs (Castro et al. 2005; Rockel et al. 2008), it is essential to investigate whether RCMs are effectively able to add value, at regional scale, to the performances of GCMs over the present climate, before applying them for climate projections. An increasing number of works (e.g. Kim et al. 2002; Diallo et al. 2012; Paeth and Mannig 2012; Diaconescu and Laprise 2013; Crétat et al. 2013; Laprise et al. 2013; Lee et al. 2014) have recently investigated the added value of downscaling GCMs, which is expected to be found in the fine scales and in the ability of RCM to simulate extreme events (Diaconescu and Laprise 2013).

Here we use the COSMO-CLM (CCLM) RCM over the CORDEX-Africa domain to downscale the simulations of four CMIP5 GCMs and we compare the results of CCLM to those of the driving GCMs over the present climate. It is important first to generally evaluate the ability of CCLM to reproduce the general characteristics of the African climate (e.g., seasonal distribution of temperature and precipitation, and WAM climatology) and, second, to investigate whether the downscaled simulations add value to the ones by the driving GCMs. Therefore, we focus not only on the main climate statistics, but we investigate also the ability of CCLM to reproduce precipitation variability and probability distribution functions (PDF), and, finally, indices such as the number of consecutive wet and dry days, and the frequency of heavy rain events.

The analysis of the projections of future climate change will be presented in a forthcoming work.

The paper is structured as follows: Sect. 2 describes the model set-up and the data used in the evaluation. In Sect. 3 results are shown and discussed. Concluding remarks are presented in Sect. 4.

\section{Model description, setup and observational data}

In this study the three-dimensional non-hydrostatic regional climate model COSMO-CLM (CCLM) is used, in the same configuration as the 'evaluation runs' (i.e., forced by the ERA-Interim reanalysis) described in Panitz et al. (2014). Here, therefore, only the main characteristics are only briefly described.

Numerical integration is performed on an Arakawa-C grid with a Runge-Kutta scheme, using the time splitting method by Wicker and Skamarock (2002), with a time step of $240 \mathrm{~s}$. A vertical hybrid coordinate system with 35 levels is used, with the upper most layer at $30 \mathrm{~km}$ above sea level. The main physical parameterizations include: the radiative transfer scheme by Ritter and Geleyn (1992); the Tiedtke parameterization of convection (Tiedtke 1989) being modified by D. Mironow (German Weather Service); a turbulence scheme (Raschendorfer 2001; Mironov and 
Fig. 1 Model domain and topography (m) of the CORDEX Africa simulations. The domain includes a sponge zone of 10 grid points in each direction. Squares indicate the locations of the evaluation regions as defined in http://www.smhi.s e/forskning/forskningsomraden/ klimatforskning/1.11299)

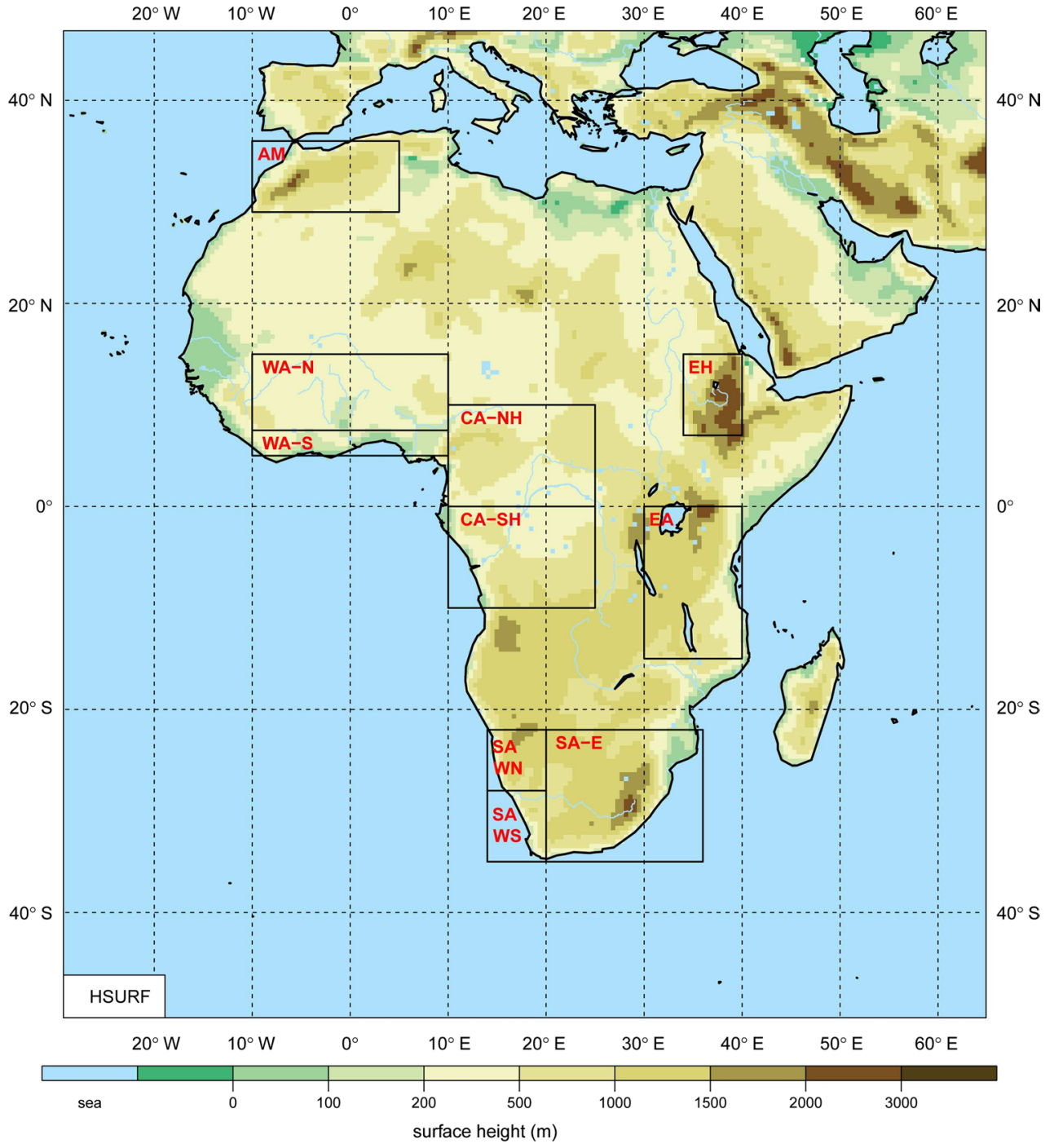

Raschendorfer 2001) based on prognostic turbulent kinetic energy closure at level 2.5 according to Mellor and Yamada (1982); a one-moment cloud microphysics scheme, a reduced version of the parameterization of Seifert and Beheng (2001); a multi layer soil model (Schrodin and Heise 2001, 2002; Heise et al. 2003); subgrid scale orography processes (Schulz 2008; Lott and Miller 1997). After a series of sensitivity runs, the lower height of the damping layer was increased from its standard value, $11 \mathrm{~km}$, to the approximate height of the tropical tropopause, $18 \mathrm{~km}$, in order to avoid unphysical and unrealistic results. Also the soil albedo was replaced by a new dataset, derived from MODIS (Moderate Resolution Imaging Spectroradiometer) (Lawrence and Chase 2007), which gives more realistic results over the deserts. A thorough description of the dynamics, numerics and physical parametrizations can be found in the model documentation (e.g., Doms 2011).

The numerical domain, common to all groups participating to the CORDEX-Africa initiative, covers the entire
African continent at a spatial resolution of $0.44^{\circ}$ (Fig. 1): thus, the model grid uses 214 points from West to East and 221 points from South to North, including the sponge zone of 10 grid points at each side, where the Davies boundary relaxation scheme is used (Davies 1976, 1983).

An ensemble of climate change projections has been created by downscaling the simulations of four GCMs from the new CMIP5 global climate projections, namely: the Max Plank Institute MPI-ESM-LR, the Hadley Center HadGEM2-ES, the National Centre for Meteorological research CNRM-CM5, and EC-Earth. The historical control runs, forced by observed natural and anthropogenic atmospheric composition, cover the period from 1950 until 2005, whereas the projections (2006-2100) are forced by two Representative Concentration Pathways (RCP) (Moss et al. 2010; Vuuren et al. 2011), namely, RCP4.5 and RCP8.5.

As mentioned, in this work we evaluate the performance of CCLM by comparing the results to those of the driving 
Table 1 Summary of available precipitation dataset used for the evaluation of the model's results

\begin{tabular}{lllllll}
\hline Name & Type & Variable & Time period & Time res. (highest) & Spatial res. (deg.) & References \\
\hline UDEL v2.01 & Obs. & T, Prec. & $1901-2008$ & Monthly & 0.5 & Legates and Willmott (1990) \\
CRU v3.0 & Obs. & T, Prec. & $1901-2006$ & Monthly & 0.5 & Mitchell and Jones (2005) \\
GPCC v5 & Obs. & Prec. & $1951-2009$ & Monthly & 0.5 & Rudolf et al. (2010) \\
GPCP v1.1 & Satellite/Obs. & Prec. & $1998-2010$ & Daily & 1 & Adler et al. (2003) \\
TRMM 3B42v6 & Satellite & Prec. & $1998-2010$ & 3-Hourly & 0.25 & Huffman et al. (2009) \\
\hline
\end{tabular}

GCMs over the present climate (1989-2005). High-quality observational datasets for Africa are scarce, and significant discrepancies exist amongst different datasets mainly due, for instance, to the limited number of gauge stations, retrieval, merging, and interpolation techniques (Huffman et al. 2009; Nikulin et al. 2012; Sylla et al. 2012). Here, a combination of available ground observations, satellite products, and reanalysis is used, as done in Panitz et al. (2014), where a critical review of the available observational dataset for Africa was presented. A list of the datasets used in this study is reported in Table 1.

Several evaluation sub-regions have been defined in the CORDEX protocol (see Fig. 1, and http://www.smhi.se/fors kning/forskningsomraden/klimatforskning/1.11299), which have been used in previous single- and multi-model evaluation studies over CORDEX-Africa (e.g Nikulin et al. 2012; Laprise et al. 2013). Similarly, seasonal statistics have been calculated for boreal winter (January-February-MarchJFM) and summer (July-August-September-JAS).

\section{Results}

In this section we critically analyze the ability of CCLM, forced by different GCMs, to reproduce the principal characteristics of the African climatology. It is important to note that the skill of an RCM driven by a GGM must be viewed as the skill of the GCM-RCM combination, and as such, the difference between the forcing and the downscaled data can be used to identify added value. We first discuss the geographical and temporal distribution of mean sea level pressure (MSLP), temperature and precipitation. We also compare spatial and temporal statistics (Bias, RMSE, Pattern Correlation, and interannual variability) of seasonal temperature and precipitation. Subsequently, annual cycles of daily precipitation are investigated over selected regions, together with the WAM main characteristics. In order to compare the ability of GCMs and RCM to simulate the dominant components (temporal scales) of the annual evolution of the WAM, a singular spectral analysis (SSA) is performed for the daily precipitation time series over region WA_S (see Fig. 1) along the Gulf of Guinea. Standard deviation and PDFs of daily precipitation have been also calculated. Finally, some precipitation indices are also evaluated, such as the number of consecutive wet and dry days, and the frequency of heavy rain events.

\subsection{Seasonal climatology}

Models' bias of seasonally averaged MSLP are shown in Fig. 2. Compared to the reanalysis, GCMs tend to overestimate the meridional pressure gradient in JFM: in particular, HadGEM2-ES values are too high over north-equatorial Africa and too low over central and southern Africa, CNRM-CM5 generally underestimates MSLP over central and southern Africa (and the Atlantic Ocean), whereas MPI-ESM-LR overestimates MSLP over the Sahel and Sahara regions. Only EC-Earth performs satisfactorily over nearly all the land areas, although MSLP is underestimated over the Atlantic. As discussed by Panitz et al. (2014), CCLM performs rather satisfactorily when driven by the reanalysis, with generally small biases $(<2 \mathrm{hPa})$; however, as for the GCMs, CCLM tends to overestimate MSLP over the Sahara and underestimate it over Central and South Africa. This behaviour, in addition to the bias inherited by the forcing GCMs, results in a deterioration of the bias over the Sahara for CNRM-CM5 and EC-Earth and over central and south Africa for EC-Earth, resulting in a exaggerated pressure gradient between northern and central Africa.

In JAS, both CNRM-CM5 and EC-Earth show too low values of MSLP over the majority of the land areas and oceans, whereas the Sahara Heat Low is too weak for HadGEM2-ES and MPI-ESM-LR, which may result in an underestimation of the land-sea pressure gradient and, in turn, the WAM (Brands et al. 2013). CCLM partly corrects some of the GCMs' biases over land, especially over the Sahel and Central Africa, except for the EC-Earth downscaling, which does not show a significant improvement compared to the driving field.

In a recent work, Laprise et al. (2013) noted that MPIESM-LR (and CanESM2, the other GCM used in their study) tend to overestimate the Sea Surface Temperature (SST) over the Guinea Gulf and the West coast of subequatorial Africa. Brands et al. (2013) also noted the same overestimation of $(2 \mathrm{~m})$ sea temperature in all the analyzed GCMs (including MPI-ESM-LR, CNRM-CM5, and 

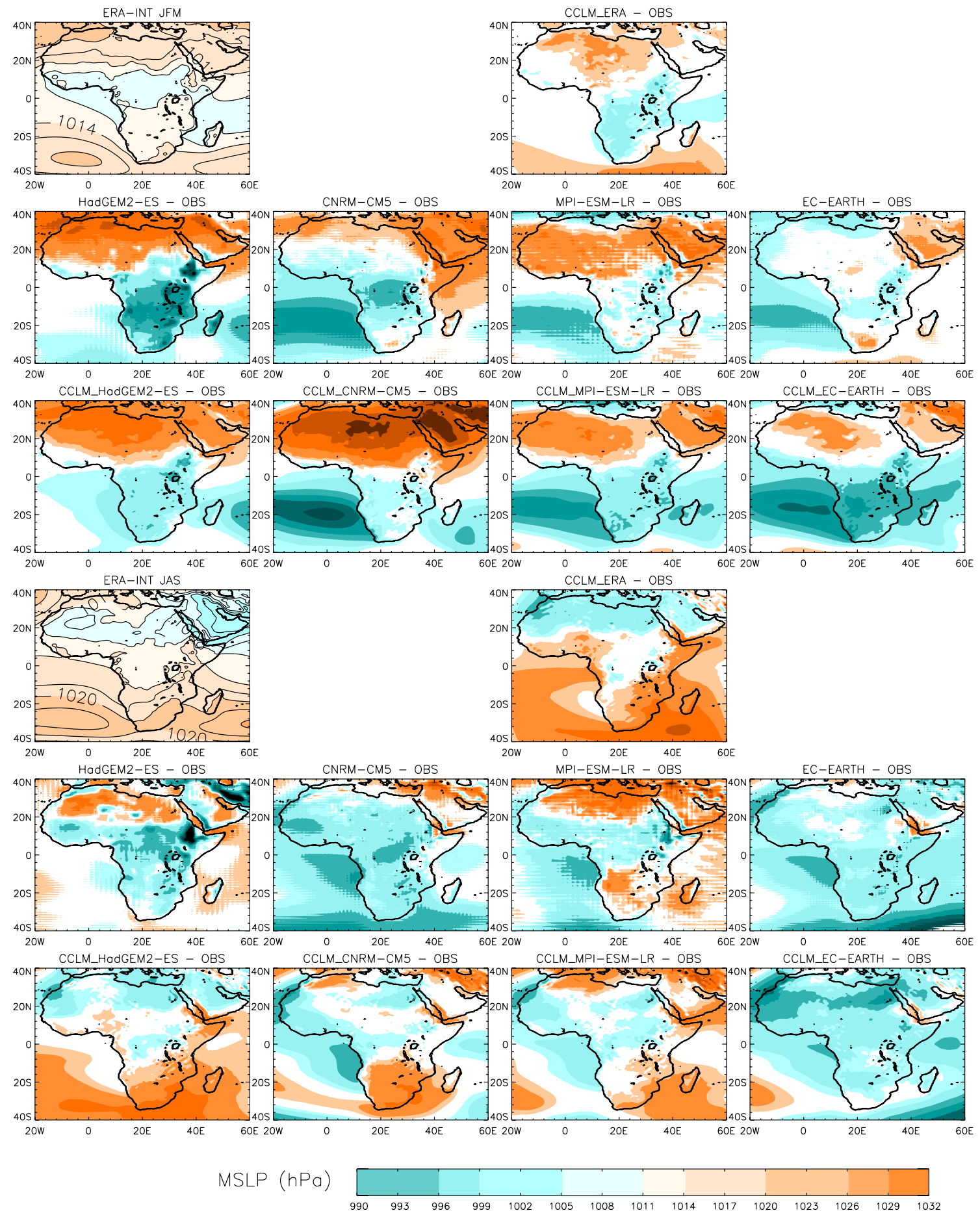

$\operatorname{Bias}(\mathrm{hPa})$

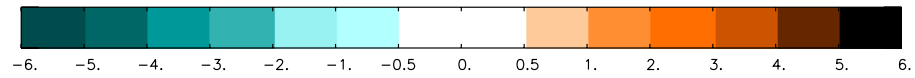

Fig. 2 Bias of mean sea level pressure (MSLP), compared to ERAinterim (used as observation), for the GCMs and CCLM, for austral (JFM) and boreal (JAS) summer (top three and bottom three rows, respectively). ERA-interim data also shown for comparison. In addition, the bias of the evaluation run (CCLM forced by ERA-interim) is shown 
HadGEM2-ES). In addition, by analyzing the wind components at both 500 and $800 \mathrm{hPa}$ they found that GCMs usually underestimate the monsoonal winds over the Sahel during the core of the WAM, producing also too strong Subtropical Jet and a too weak African Easterly Jet. These misrepresentations of the circulation are introduced as boundary conditions to CCLM, with repercussion on, for instance, the precipitation and WAM climatology, as it will be discussed.

The JFM $2 \mathrm{~m}$ temperature bias is shown in Fig. 3. Compared to the UDEL observations, CCLM driven by ERAInterim performs, in general, satisfactorily, and similarly to other RCMs (Kim et al. 2013). However, CCLM shows a cold bias over the Sahara and North Africa region, and a weak warm bias over central and southern Africa. All GCMs tend to underestimate $2 \mathrm{~m}$ temperature over land, with EC-Earth showing an extended cold bias over all the continent, while both CNRM-CM5 and HadGEM2-ES underestimate temperature over north-equatorial and South Africa, and slightly overestimate it over the Congo region. MPI-ESM-LR performs better than the other GCMs, although a general cold bias is evident, especially along the coast of the Guinea Gulf. CCLM is generally not able to correct the bias, which, in some cases, e.g., the band around $20^{\circ} \mathrm{N}$, is even worsened as a result of the combination of both GCM' and CCLM' cold biases over the region.

In order to quantify the ability of CCLM to improve (or not) over the GCMs' results, Added Value is defined, adapting from Di Luca et al. (2012)) as:

$A V=\frac{\left(X_{G C M}-X_{O B S}\right)^{2}-\left(X_{C C L M}-X_{O B S}\right)^{2}}{\operatorname{Max}\left(\left(X_{G C M}-X_{O B S}\right)^{2},\left(X_{C C L M}-X_{O B S}\right)^{2}\right)}$,

so that $\mathrm{AV}$ is positive where CCLM's squared error is smaller than the GCM's one. The normalization is introduced so that $-1 \leq \mathrm{AV} \leq 1$. Results depend strongly on the downscaled GCM (Fig. 3): for instance, CCLM improves the performances of HadGEM2-ES over north-equatorial Africa and those of EC-Earth over sub-equatorial Africa. However, CCLM's square error is similar to the GCMs' ones over central Africa (for HadGEM2-ES, CNRM-CM5 and MPI-ESM-LR) but worse over north-equatorial Africa, especially for MPI-ESM-LR and EC-Earth.

Spatial statistics of JFM temperature are reported in Table 2, where bias, RMSE, and Pattern Correlation are shown for continental and, separately, north-and subequatorial Africa. UDEL is used as reference dataset as its statistical values over the period considered (1989-2005) are very similar to e.g., CRU. We note that, except for HadGEM2-ES, CCLM generally deteriorates the bias and RMSE of the driving GCMs, although large geographical differences exist; for instance, for EC-Earth, CCLM enlarges the cold bias in North-Africa (from -2.2 to $-3.5^{\circ} \mathrm{C}$ ) but reduces the one over sub-equatorial Africa (from -3.6 to $-2.6^{\circ} \mathrm{C}$ ). Pattern correlation is usually very high (above 0.9) for both GCMs and CCLM, although the RCM clearly improves the correlation over sub-equatorial Africa compared to all the driving GCMs.

Table 3 shows the temporal standard deviation (calculated over the period 1989-2005) of JFM temperature, which is a measure of the interannual variability (Lee and Hong 2013; Kim et al. 2013). Both GCMs' and RCM's values are relatively close to the observed ones (UDEL), with CCLM slightly improving over HadGEM2-ES and MPI-ESM-LR.

In JAS (Fig. 4), CCLM driven by ERA-Interim shows a marked warm bias over the Sahara and Angola, and a cold bias over the Guinea region and southern Sahel. As discussed by Panitz et al. (2014) this can be related to an incorrect representation of the cloud diurnal cycle and overestimation of the convective activity. The GCMs performances are heterogeneous, with EC-Earth showing a general marked cold bias, CNRM-CM5 and HadGEM2ES underestimating temperature over the Sahara and South Africa, and MPI-ESM-LR showing a warm bias over Mauritania extending eastwards along $10^{\circ} \mathrm{N}$. From the analysis of the squared error (Eq. 1) we note that CCLM reduces the cold bias over South Africa, for all GCMs, and over the Sahara region, especially for HadGEM2-ES and EC-Earth forcings. The temperature underestimation over the Guinea Gulf is, however, still present and, in some cases, increased, especially for HadGEM2-ES and CNRM-CM5. Spatial statistics (Table 2) confirm a marked reduction in the cold bias for HadGEM2-ES (from -0.9 to $-0.3^{\circ} \mathrm{C}$ ), especially for north-equatorial Africa (from -1.2 to $-0.3^{\circ} \mathrm{C}$ ). For CNRM-CM5 the bias is reduced from -1.9 to $-1.2^{\circ} \mathrm{C}$ over sub-equatorial Africa, but increases from from -1.1 to $-1.6^{\circ} \mathrm{C}$ elsewhere, whereas for EC-Earth the opposite is true, with the bias passing from -2.6 to $-2.2 \mathrm{C}$ over north-equatorial Africa and from -1.2 to $-1.6^{\circ} \mathrm{C}$ over subequatorial Africa. Spatial correlation improves for CCLM compared to HadGEM2-ES, especially over north-equatorial Africa, whereas for the other GCMs values are similar or only slightly better. A slight reduction in the correlation is noted for CCLM driven by CNRM-CM5. CCLM's interannual variability (Table 3 ) is relatively similar to that of the driving GCMs over continental Africa, with a marked improvement (from 0.47 to 0.40, UDEL's value being 0.34) only for MPI-ESM-LR. Over north-equatorial Africa CCLM values are closer to the observed ones for all GCMs but EC-Earth.

From this analysis it is evident that it is very difficult to discern a systematic and homogeneous improvement of performances of the downscaled simulations over the GCMs' ones. Mariotti et al. (2011) suggest that surface temperature (especially over such a large domain as Africa) is more influenced by the RCM's internal processes rather 

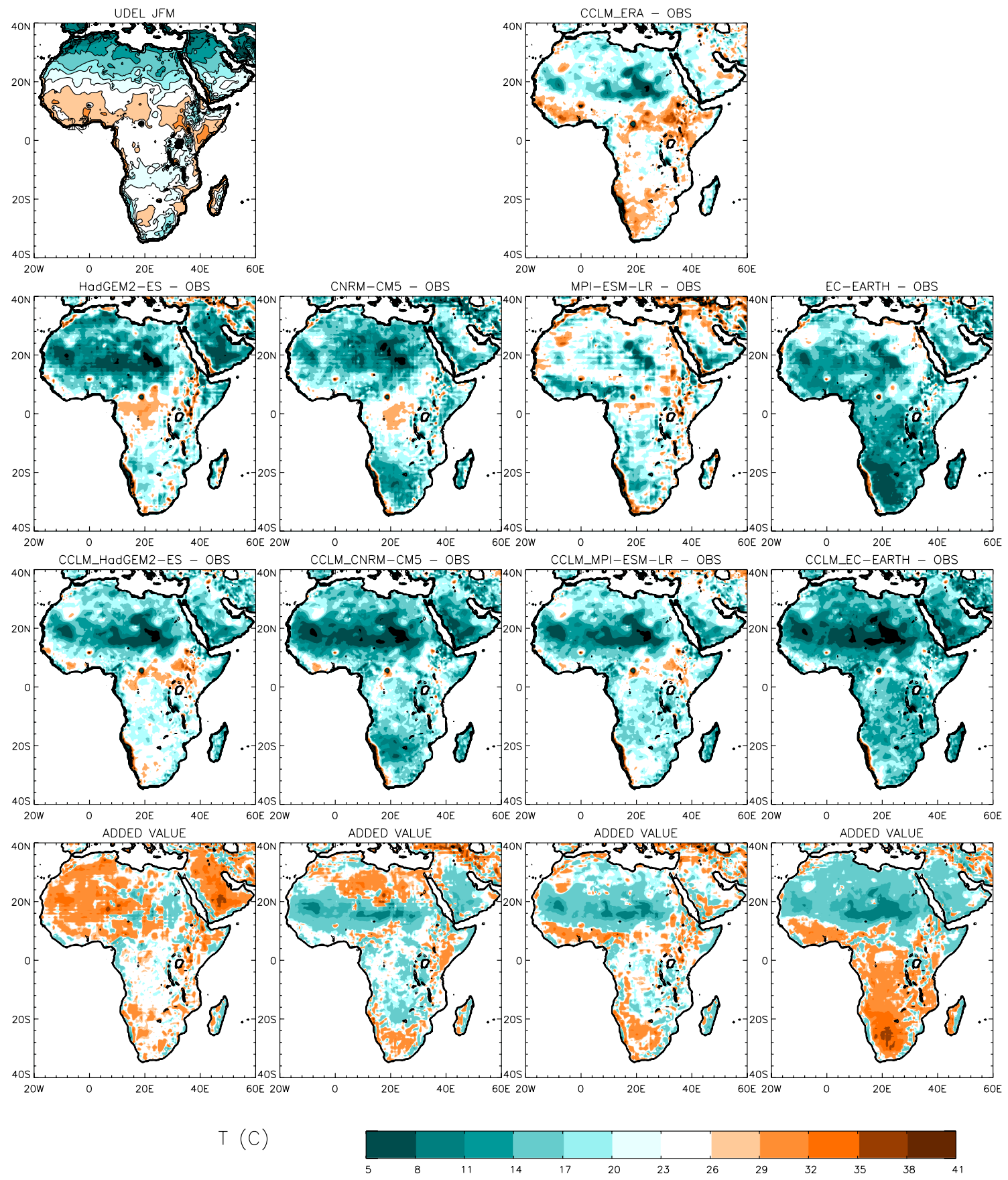

Bias (C)

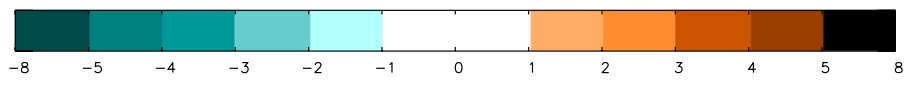

Added Value

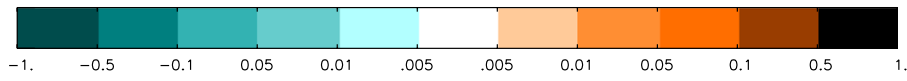

Fig. 3 Bias of $2 \mathrm{~m}$ temperature in JFM, compared to UDEL, for the GCMs and CCLM. In the first row, UDEL values and the bias of the evaluation run (i.e CCLM forced by ERA-interim) are shown. The last row shows the added value adapted from Di Luca et al. (2012)) (Eq. 1)

than the forcing through lateral boundary conditions. Our results are somehow in agreement with these findings, especially over areas, such as the Sahel, where CCLM's bias seems to be independent of the driving GCM. Over other areas, CCLM's own structural bias (i.e. the one of the evaluation run driven by ERA-Interim) is added to that 
Table 2 Spatial statistics of seasonal temperature $\left({ }^{\circ}\right)$, averaged over continental Africa (land points only)

\begin{tabular}{|c|c|c|c|c|c|c|c|c|}
\hline & HadGEM2-ES & CCLM & CNRM-CM5 & CCLM & MPI-ESM-LR & CCLM & EC-EARTH & CCLM \\
\hline \multicolumn{9}{|l|}{$J F M$} \\
\hline BIAS & $\begin{array}{l}-2.0 \\
(-2.5,-0.6)\end{array}$ & $\begin{array}{l}-1.6 \\
(-2.0,-0.7)\end{array}$ & $\begin{array}{l}-2.1 \\
(-2.4,-1.5)\end{array}$ & $\begin{array}{l}-2.7 \\
(-3.1,-2.0)\end{array}$ & $\begin{array}{l}-0.7 \\
(-0.7,0.8)\end{array}$ & $\begin{array}{l}-1.9 \\
(-2.1,-1.4)\end{array}$ & $\begin{array}{l}-2.6 \\
(-2.2,-3.6)\end{array}$ & $\begin{array}{l}-3.2 \\
(-3.5,-\mathbf{2 . 6})\end{array}$ \\
\hline RMSE & $\begin{array}{l}2.3 \\
(3.1,1.1)\end{array}$ & $\begin{array}{l}1.9 \\
(2.6,0.9)\end{array}$ & $\begin{array}{l}2.1 \\
(2.7,1.4)\end{array}$ & $\begin{array}{l}2.5 \\
(3.2, \mathbf{1 . 4})\end{array}$ & $\begin{array}{l}1.5 \\
(1.8,1.2)\end{array}$ & $\begin{array}{l}1.9 \\
(2.5, \mathbf{1 . 1})\end{array}$ & $\begin{array}{l}2.3 \\
(2.5,2.3)\end{array}$ & $\begin{array}{l}2.7 \\
(3.5, \mathbf{1 . 7})\end{array}$ \\
\hline CORR & $\begin{array}{l}0.902 \\
(0.961,0.699)\end{array}$ & $\begin{array}{l}\mathbf{0 . 9 3 1} \\
(0.939, \mathbf{0 . 9 4 5})\end{array}$ & $\begin{array}{l}0.934 \\
(0.949,0.661)\end{array}$ & $\begin{array}{l}0.928 \\
(0.937, \mathbf{0 . 7 6 1})\end{array}$ & $\begin{array}{l}0.926 \\
(0.941,0.642)\end{array}$ & $\begin{array}{l}\mathbf{0 . 9 3 2} \\
(0.939, \mathbf{0 . 7 9 6})\end{array}$ & $\begin{array}{l}0.931 \\
(0.954,0.679)\end{array}$ & $\begin{array}{l}\mathbf{0 . 9 3 4} \\
(0.941, \mathbf{0 . 8 0 0})\end{array}$ \\
\hline \multicolumn{9}{|l|}{$J A S$} \\
\hline BIAS & $\begin{array}{l}-0.9 \\
(-1.2,-0.1)\end{array}$ & $\begin{array}{l}-0.3 \\
(-0.3,-0.5)\end{array}$ & $\begin{array}{l}-1.3 \\
(-1.1,-1.9)\end{array}$ & $\begin{array}{l}-1.5 \\
(-1.6,-\mathbf{1 . 2})\end{array}$ & $\begin{array}{l}0.3 \\
(0.7,-0.6)\end{array}$ & $\begin{array}{l}-0.5 \\
(-0.6,-0.4)\end{array}$ & $\begin{array}{l}-2.2 \\
(-2.6,-1.2)\end{array}$ & $\begin{array}{l}-2.0 \\
(-2.2,-1.6)\end{array}$ \\
\hline RMSE & $\begin{array}{l}1.9 \\
(2.5,1.1)\end{array}$ & $\begin{array}{l}1.6 \\
(2.0,1.1)\end{array}$ & $\begin{array}{l}1.7 \\
(1.8,1.6)\end{array}$ & $\begin{array}{l}1.9 \\
(2.4,1.2)\end{array}$ & $\begin{array}{l}1.6 \\
(2.0,1.2)\end{array}$ & $\begin{array}{l}1.5 \\
(1.9,1.0)\end{array}$ & $\begin{array}{l}2.2 \\
(2.9,1.2)\end{array}$ & $\begin{array}{l}\mathbf{2 . 1} \\
(2.7,1.3)\end{array}$ \\
\hline CORR & $\begin{array}{l}0.907 \\
(0.792,0.884)\end{array}$ & $\begin{array}{l}0.943 \\
(0.902,0.907)\end{array}$ & $\begin{array}{l}0.949 \\
(0.906,0.895)\end{array}$ & $\begin{array}{l}0.932 \\
(0.877,0.0 .844)\end{array}$ & $\begin{array}{l}0.935 \\
(0.868,0.869)\end{array}$ & $\begin{array}{l}0.944 \\
(0.909,0.892)\end{array}$ & $\begin{array}{l}0.928 \\
(0.869,0.910)\end{array}$ & $\begin{array}{l}0.936 \\
(0.888,0.910)\end{array}$ \\
\hline
\end{tabular}

In brackets, values for north-equatorial and sub-equatorial Africa, respectively. UDEL has been used as refernce dataset. CCLM's skill scores are highlited in bold if equal or better than the respective GCM

Table 3 Interannual variability (standard deviation) of seasonal temperature $\left(^{\circ}\right.$ ), averaged over continental Africa (land points only) calculated over the period 1989-2005

\begin{tabular}{lllllllll}
\hline & HadGEM2-ES & CCLM & CNRM-CM5 & CCLM & MPI-ESM-LR & CCLM & EC-EARTH & CCLM \\
\hline UDEL JFM & & & & & & & \\
0.47 & 0.53 & $\mathbf{0 . 4 7}$ & 0.48 & 0.39 & 0.50 & $\mathbf{0 . 4 5}$ & 0.42 & 0.36 \\
$(0.72,0.23)$ & $(0.81,0.23)$ & $\mathbf{( 0 . 7 2 , \mathbf { 0 . 2 3 } )}$ & $(0.77,0.20)$ & $(0.62,0.17)$ & $(0.76,0.25)$ & $\mathbf{( 0 . 7 0 , \mathbf { 0 2 0 } )}$ & $(0.63,0.21)$ & $(0.57,0.15)$ \\
UDEL JAS & & & & & & & \\
0.34 & 0.41 & $\mathbf{0 . 3 9}$ & 0.34 & $\mathbf{0 . 3 4}$ & 0.47 & $\mathbf{0 . 4 0}$ & 0.43 & 0.44 \\
$(0.49,0.19)$ & $(0.57,0.24)$ & $\mathbf{( 0 . 5 2}, 0.26)$ & $(0.51,0.17)$ & $\mathbf{( 0 . 4 8 , 0 . 1 9 )}$ & $(0.69,0.26)$ & $\mathbf{( 0 . 5 5 , \mathbf { 0 . 2 5 } )}$ & $(0.63,0.23)$ & $(0.67, \mathbf{0 . 2 1})$ \\
\hline
\end{tabular}

In brackets, values for north-equatorial and sub-equatorial Africa, respectively. Values calculated for the UDEL dataset are also reported. CCLM's skill scores are highlited in bold if equal or better than the respective GCM

of the driving GCM: this can result in an improvement but also in a deterioration of the temperature bias.

The bias of seasonally averaged daily precipitation in JFM is shown in Fig. 5. GCMs reproduce precipitation in an heterogeneous way; in particular, precipitation is overestimated over South Africa for CNRM-CM5, MPI-ESM-LR, and EC-Earth, and over the western sub-equatorial coast for MPI-ESM-LR. On the other hand, a dry bias is shown over central Africa for HadGEM2-ES and CNRM-CM5, and over Madagascar and Mozambique for MPI-ESM-LR and EC-Earth. However, the most striking feature is the general misplacement of the monsoonal rainbelt, which is located too southwards for EC-Earth, MPI-ESM-LR and CNRMCM5, with the latter also overestimating the rainbelt width. Only HadGEM2-ES reproduces correctly the position of the monsoon band, although slightly underestimating its intensity over the Gulf of Guinea. CCLM is clearly influenced by the boundary conditions as the position of the rainbelt resembles clearly that of the driving GCM. In addition, CCLM tends to overestimate precipitation over the ocean, as already noticed in the ERA-Interim driven simulation. CCLM results over land show an added value (according to Eq. 1) over southern Africa, especially when compared to CNRM-CM5, MPI-ESM-LR and EC-Earth; here the wet bias is removed or, at least, reduced. Over the Congo area, results are mixed, although a improvement is visible at least for the HadGEM2-ES downscaled simulation, as shown by the Added Value, which is positive. In the fascia between the equator and $10^{\circ} \mathrm{N}$ (including the Guinea coast) CCLM remains consistently too dry, as for the evaluation run (Nikulin et al. 2012; Kim et al. 2013; Panitz et al. 2014).

Spatial statistics of JFM daily precipitation are reported in Table 4 where GGMs' and CCLM's values are compared to those of several observational datasets. Sylla et al. (2012) and Panitz et al. (2014) discussed the availability of precipitation data in Africa and analyzed different 

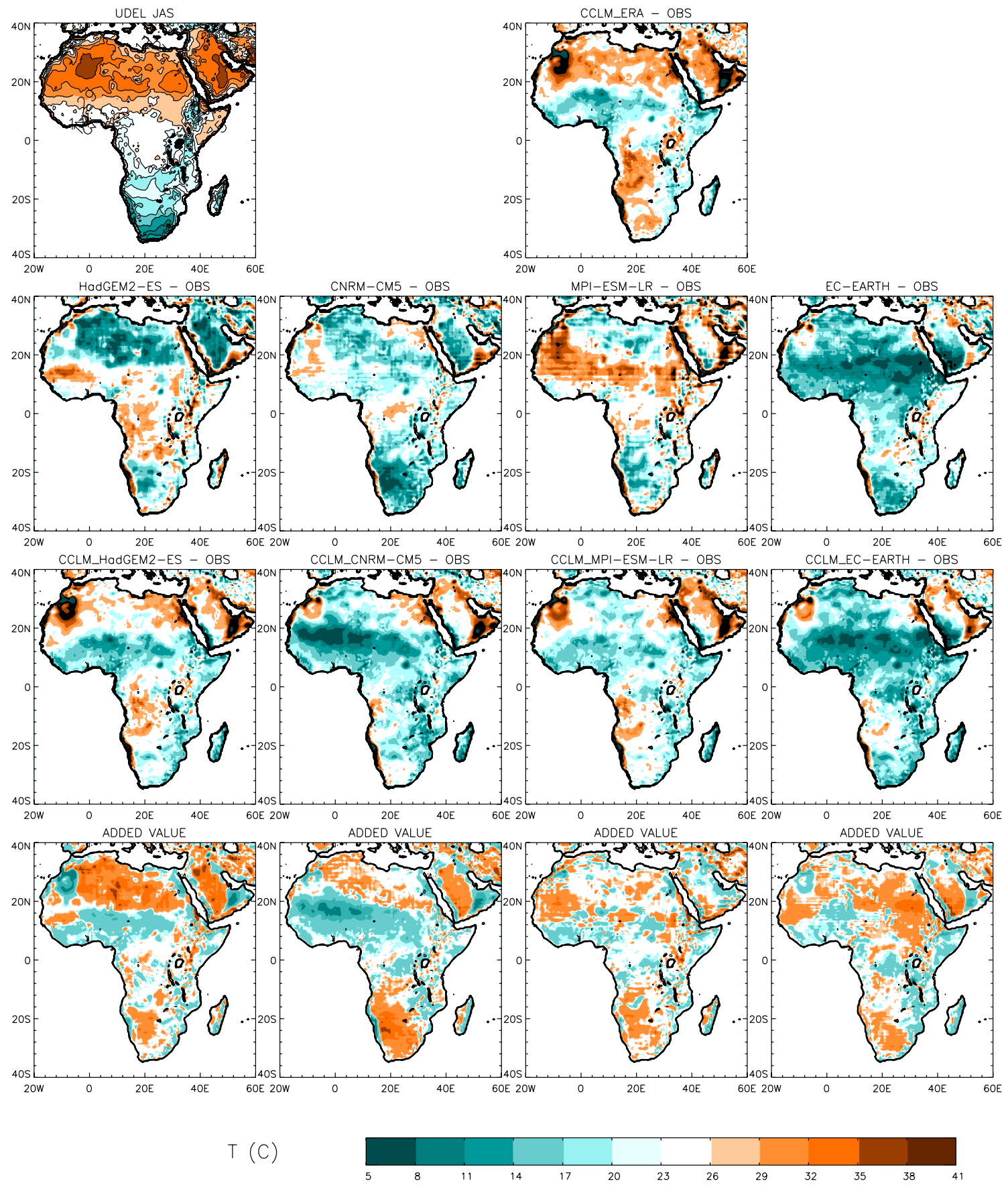

Bias (C)

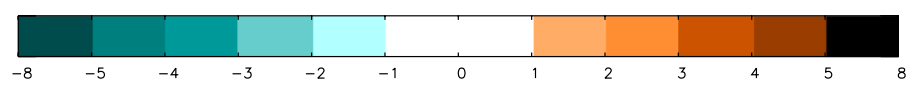

Added Value

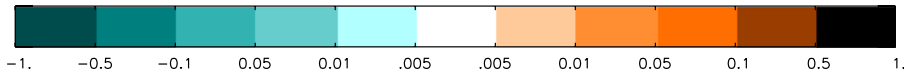

Fig. 4 As Fig. 3 but for boreal summer (JAS)

precipitation datasets. They found that, although the geographical distribution is generally similar amongst different sets, large discrepancies exist locally. By using GPCC as a reference, the bias in JFM precipitation varies between
$-0.16 \mathrm{~mm} /$ day (TRMM) and $0.09 \mathrm{~mm} /$ day (GPCP) (Table 4). CCLM's bias varies between -0.06 and $-0.5 \mathrm{~mm} /$ day, with a deterioration compared to HadGEM2-ES (due to the large dry bias over Mozambique and Madagascar 

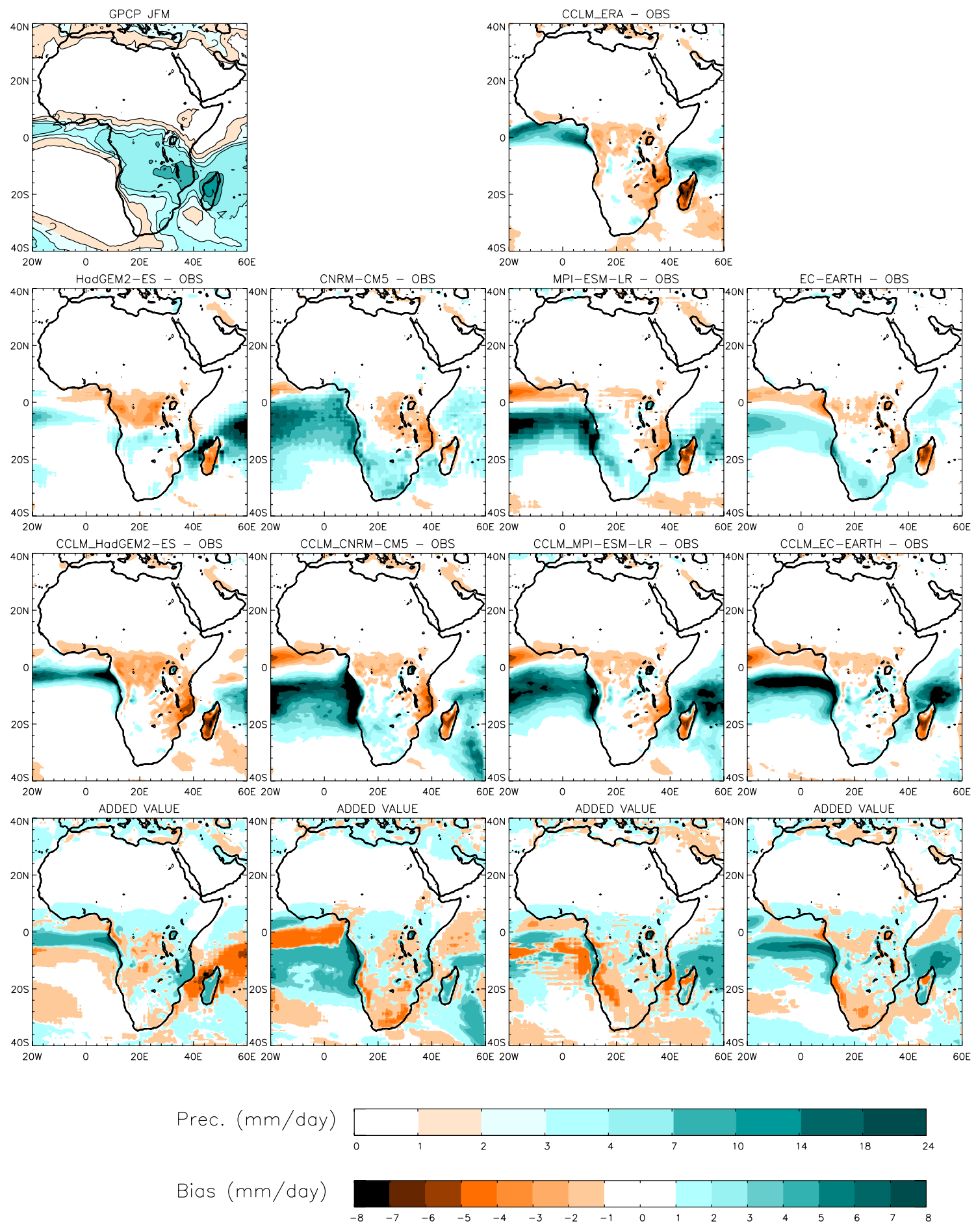

Added Value

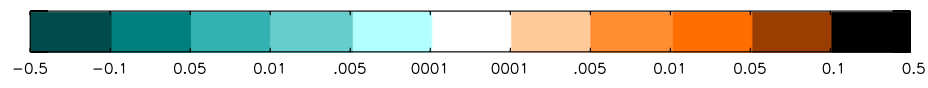

Fig. 5 Bias of daily precipitation in JFM, compared to GPCP, for the GCMs and CCLM. In the first row, GPCP values and the bias of the evaluation run (i.e CCLM forced by ERA-interim) are shown. The last row shows the added value adapted from Di Luca et al. (2012) (Eq. 1)

for CCLM) and MPI-ESM-LR (although in this case the RMSE is improved). Compared to CNRM-CM5 and ECEarth, the absolute value of CCLM's bias is very similar, but opposite in sign, with the downscaled runs being always too dry over land. Observed interannual variability over the period 1989-2005 varies between $0.27 \mathrm{~mm} /$ day (CRU) and 
Table 4 Spatial statistics of seasonal precipitation (mm/day), averaged over continental Africa (land points only), in JFM (upper rows) and JAS (bottom rows)

\begin{tabular}{|c|c|c|c|c|c|c|c|c|}
\hline JFM & HadGEM2-ES & CCLM & CNRM-CM5 & CCLM & MPI-ESM-LR & CCLM & EC-EARTH & CCLM \\
\hline BIAS & -0.19 & -0.50 & 0.16 & -0.13 & -0.01 & -0.20 & 0.05 & -0.06 \\
\hline RMSE & 0.69 & 0.91 & 0.93 & 0.98 & 0.91 & 0.82 & 0.76 & 0.76 \\
\hline CORR & 0.926 & 0.913 & 0.935 & 0.980 & 0.919 & 0.815 & 0.765 & 0.766 \\
\hline JFM & GPCP & TRMM & UDEL & CRU & & & & \\
\hline BIAS & 0.09 & -0.16 & -0.04 & -0.03 & & & & \\
\hline RMSE & 0.34 & 0.42 & 0.26 & 0.29 & & & & \\
\hline CORR & 0.981 & 0.975 & 0.988 & 0.985 & & & & \\
\hline JAS & HadGEM2-ES & CCLM & CNRM-CM5 & CCLM & MPI-ESM-LR & CCLM & EC-EARTH & CCLM \\
\hline BIAS & -0.19 & -0.17 & 0.44 & 0.53 & -0.03 & 0.12 & 0.37 & 0.37 \\
\hline RMSE & 0.86 & 1.15 & 0.97 & 1.26 & 0.83 & 1.08 & 1.02 & 1.38 \\
\hline CORR & 0.863 & 0.837 & 0.904 & 0.857 & 0.916 & 0.868 & 0.880 & 0.824 \\
\hline JAS & GPCP & TRMM & UDEL & CRU & & & & \\
\hline BIAS & 0.12 & -0.11 & 0.06 & 0.01 & & & & \\
\hline RMSE & 0.47 & 0.53 & 0.25 & 0.29 & & & & \\
\hline CORR & 0.972 & 0.961 & 0.992 & 0.989 & & & & \\
\hline
\end{tabular}

GPCC has been used as reference dataset. Values calculated for other observational datasets are also reported. CCLM's skill scores are highlited in bold if equal or better than the respective GCM

Table 5 Interannual variability (standard deviation) of seasonal precipitation (mm/day), averaged over continental Africa in JFM and JAS (land points only)

\begin{tabular}{lllllllll}
\hline JFM & HadGEM2-ES & CCLM & CNRM-CM5 & CCLM & MPI-ESM-LR & CCLM & EC-EARTH & CCLM \\
\hline SD & 0.27 & 0.25 & 0.27 & 0.24 & 0.28 & 0.23 & 0.29 & 0.25 \\
\hline JFM & GPCC & UDEL & CRU & & & & & \\
\hline SD & 0.31 & 0.28 & 0.27 & & & & \\
\hline JAS & HadGEM2-ES & CCLM & CNRM-CM5 & CCLM & MPI-ESM-LR & CCLM & EC-EARTH & CCLM \\
\hline JAS & 0.35 & GPCC & UDEL & CRU & & 0.17 & 0.36 & $\mathbf{0 . 2 9}$ \\
\hline SD & 0.25 & 0.24 & 0.23 & 0.38 & & & & \\
\hline
\end{tabular}

Values calculated for the observational datasets available for the entire period 1989-2005 are also reported. CCLM's skill scores are highlited in bold if equal or better than the respective GCM

$0.31 \mathrm{~mm} /$ day (GPCC) (Table 5). Both GCMs and CCLM show values comparable with the observations, with CCLM's values slightly smaller than the GCMs' ones.

In JAS (Fig. 6) the rainbelt has moved to its northernmost position, located between the Equator and $15^{\circ} \mathrm{N}$. Precipitation maxima are visible over the highlands of Guinea, Cameroon and Ethiopia. GCMs reproduce the rainbelt position rather satisfactorily, although they generally overestimate precipitation intensity over the Guinea Gulf and underestimate it over the Sahel, especially HadGEM2ES. CCLM has a general dry bias over the Guinea Gulf and central Africa, as shown by the ERA-interim run; this tendency is maintained in the downscaled simulations, which do not show a clear improvement over the driving ones. This is also confirmed by the spatial statistics for JAS (Table 4) with values of CCLM's bias close to the GCMs' ones (for EC-Earth and HadGEM2-ES) or slightly worse. CCLM interannual variability, however, is always closer to the observed one than the driving GCM (Table 5).

The inability of RCMs to systematically and homogeneously improve GCMs' seasonal precipitation was also noted by Mariotti et al. (2011) and Laprise et al. (2013), 

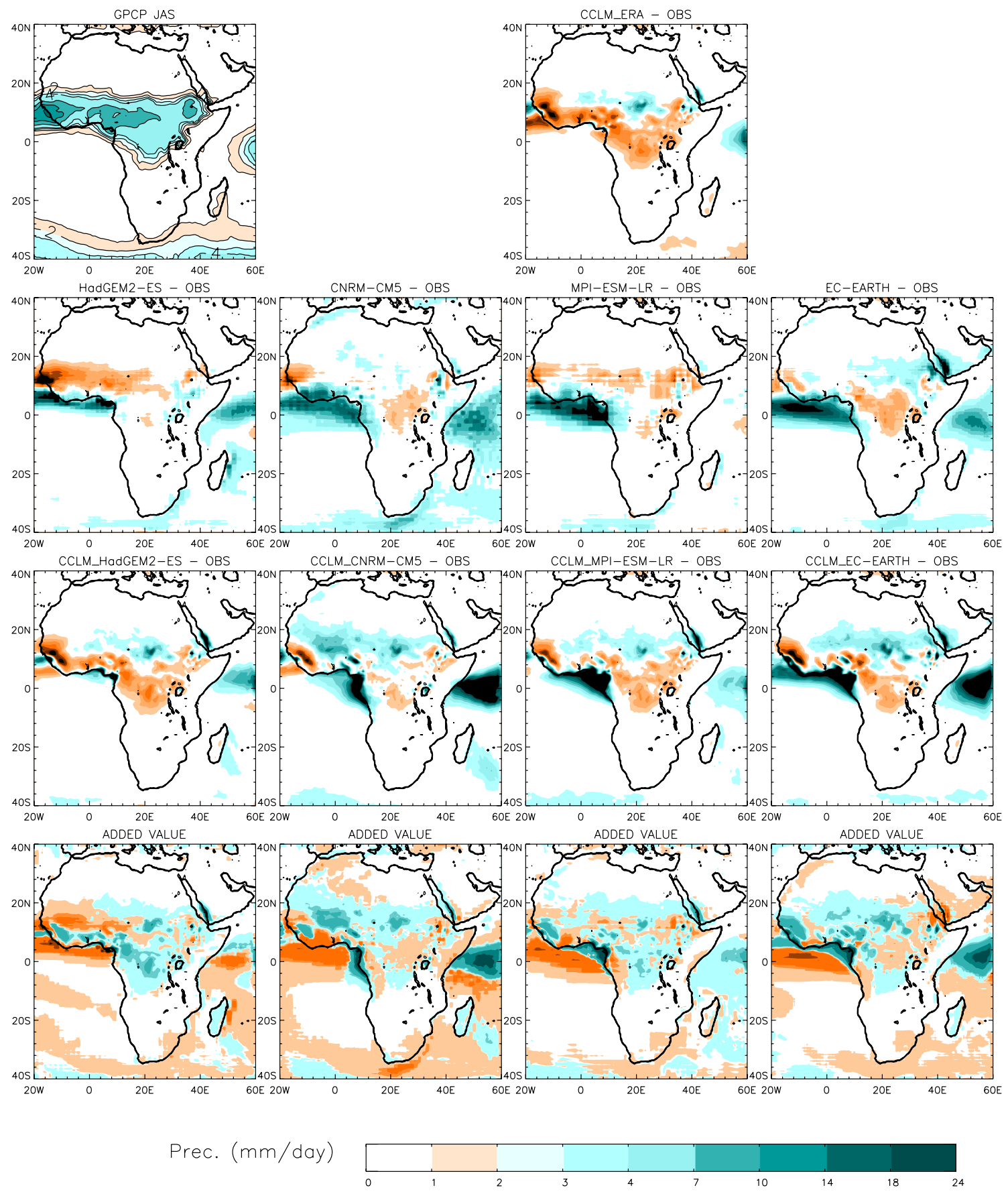

$\operatorname{Bias}(\mathrm{mm} / \mathrm{day})$

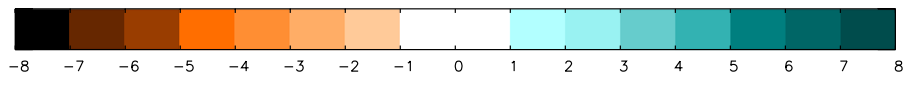

Added Value

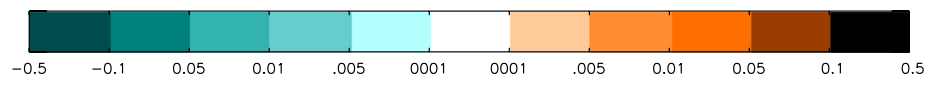

Fig. 6 As Fig. 5 but for boreal summer (JAS)

confirming that RCM processes (soil parameterization, convection schemes, etc.) play a larger role than the lateral boundary conditions on the precipitation distribution.
In addition, it is essential to remember, when evaluating the performance of a model, that uncertainty in the observations can be very large, especially over Africa, 
and the choice of the reference dataset may lead to very different results. For instance from Table 4 we note that in JFM, taking GPCP as a reference CCLM bias is always larger than that of the driving GCM; however, if TRMM is used as a reference, CCLM bias is closer to the observed one for $3 \mathrm{GCMs}$ out of $4(-0.13 \mathrm{~mm} /$ day for CCLM-CNRM-CM5, $-0.20 \mathrm{~mm} /$ day for CCLM-MPIESM-LR, $-0.06 \mathrm{~mm} /$ day for CCLM-EC-Earth, compared to $-0.16 \mathrm{~mm} /$ day for TRMM). Similarly, CCLM bias is more similar to the reference one for 2 out of 4 GCMs when compared to either UDEL of CRU. In JAS, CCLM performs similarly or better than 3 GCMs out of 4 using GPCP and UDEL, and 2 GCMs out of 4 using either TRMM or CRU. This reinforces the conclusion that when evaluating a model the use of a single observational dataset may be inconclusive, or even misleading, especially in regions such as Africa where observations are very sparse (in space and time) and therefore, not always reliable. As climate change projections are increasingly relying on large ensembles of multi-model simulations, in order to spawn the entire inter-model variability, so it should be for the observational dataset when evaluating the models performances, in order to fully address the uncertainty of observations.

\subsection{Annual cycles}

Annual cycles of daily precipitation, area-averaged over the CORDEX analysis regions, are shown in Fig. 7. The range of all the observational datasets discussed in Panitz et al. (2014) is also shown. CCLM clearly outperforms all the GCMs but HadGEM2-ES over South Africa, especially in winter and spring, where the GCM wet bias is generally corrected. Over most of the remaining regions it is difficult to assess clearly whether CCLM improves the GCMs results; for instance, over CA_SH the downscaled runs are better than the driving ones in JFM and OND, whereas over EH, CCLM-CNRM-CM5 and CCLM-ECEarth show a bimodal distribution that is neither visible in the observations nor in the results from the driving GCMs. It is worth noting that whereas over CA_NH the GCMs (and the downscaled runs) reproduce satisfactorily the bimodal distribution, which is a consequence of the passage of the monsoon rainbelt, this is not true for the WA_S region, where all the GCMs show an unimodal distribution. CCLM, on the other hand, is able to reproduce the bimodal distribution, although the first peak is overestimated (especially for EC-Earth) and the second one appears one month too late.

This ability of CCLM of reproducing the bimodal distribution over the WA_S region is further investigated by performing a Singular Spectral Analysis for the precipitation daily rate.

\subsection{Singular spectral analysis}

Singular Spectral Analysis (SSA) is a nonparametric spectral estimation method in which the original time series is decomposed into the sum of a small number of independent and interpretable components, such as slowly varying trends, oscillatory components and structureless noise (Hassani 2007). Briefly, the original time series $\{\mathrm{x}(\mathrm{t}): \mathrm{t}=1, \ldots, \mathrm{N}\}$ is first embedded in a vector space of dimension $M$ by constructing $M$-lagged vectors $\{x(t-j)$ : $\mathrm{j}=1, \ldots, \mathrm{M}\}$ thereof. The $\mathrm{M} \times \mathrm{M}$ lag-covariance matrix is then diagonalized: the resulting $\mathbf{M}$ eigenvectors $\mathbf{E}_{k}$ are called empirical orthogonal functions (EOFs), and the corresponding eigenvalues $\lambda_{k}$ account for the partial variance in the direction $\mathbf{E}_{k}$. The square root of the eigenvalues are called Singular Values and can be arranged in monotonically decreasing order: the noise level then appears in the Singular Spectrum as a flat floor at its tail (Rangarajan 1994). Projecting the time series onto each EOF yields the corresponding principal components (PCs):

$A_{k}(t)=\sum_{j=1}^{M} x(t+j) E_{k}(j), t=0, \ldots, N-M$,

which, however, have length $N^{\prime}=N-M+1$ and do not contain phase information.

The Partial Reconstruction of the original time series can be obtained by using linear combinations of the PCs and EOFs:

$x_{k}(t)=\frac{1}{M} \sum_{j=1}^{M} A_{k}(t-j) E_{k}(j)$

These series of length $\mathrm{N}$ are called reconstructed components (RCs), and the original time series can be finally obtained as:

$x(t)=\sum_{k=1}^{M} x_{k}(t)$

Results of SSA applied to daily precipitation time series for the WA_S region are shown in Fig. 8. In the figure, each column corresponds to a different GCM, together with the relative downscaled CCLM simulation, and the reference observational dataset. The first row shows the precipitation annual signal reconstructed by using the first six principal components only (Eq. 4, with $\mathrm{k}=1, \ldots, 6$ ). Second row shows the eigenvalue spectra, i.e. the percentage of variance explained as a function of $\mathrm{M}$. Note that only odd values are shown, as the singular values for sinusoidal signals appear as pairs of nearly the same value (Rangarajan 1994). Finally, the last three rows show the RCs related to the first three (odd) eigenvalues (Eq. 3, with $\mathrm{k}=1,3,5$ ) for 

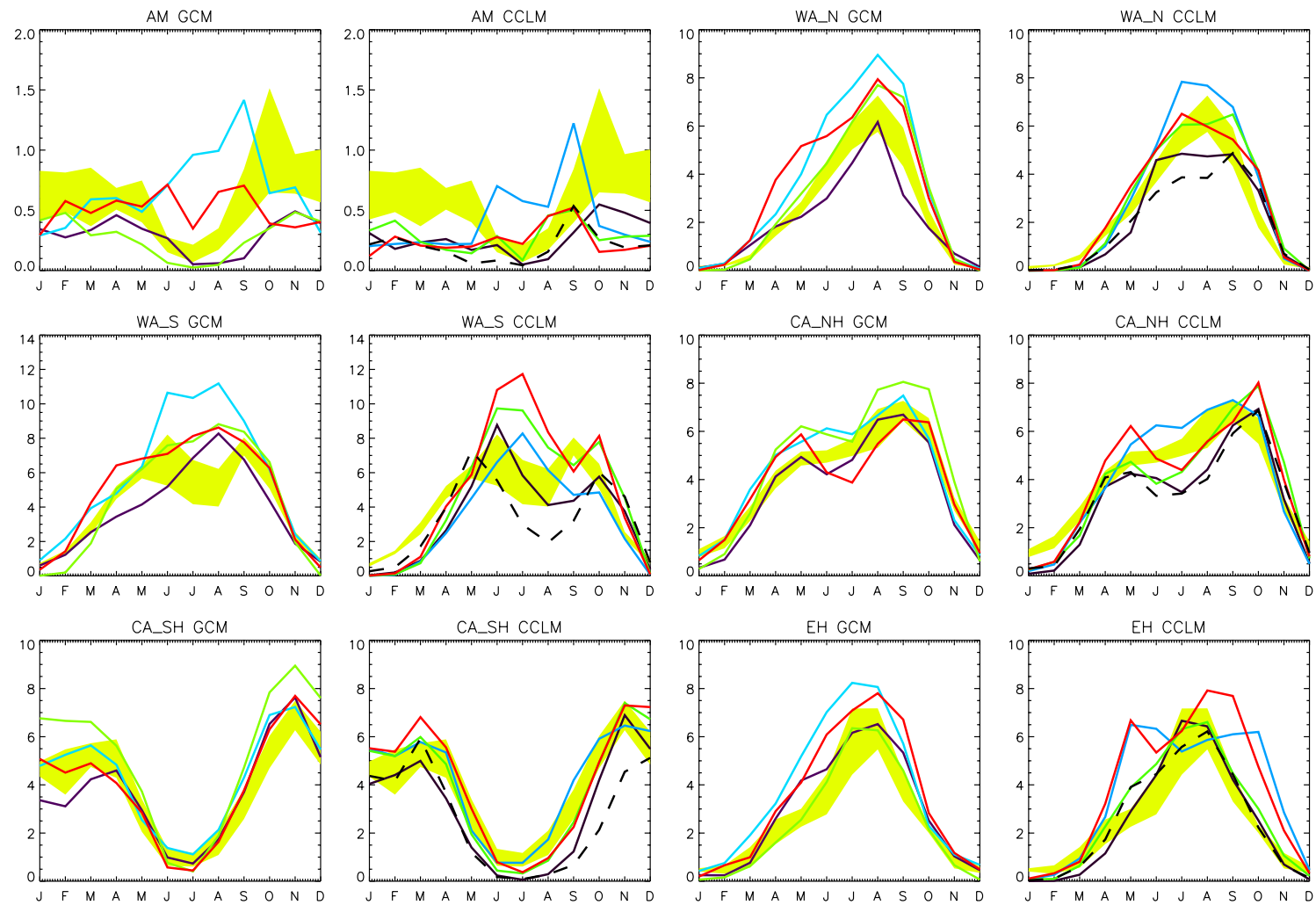

EH GCM
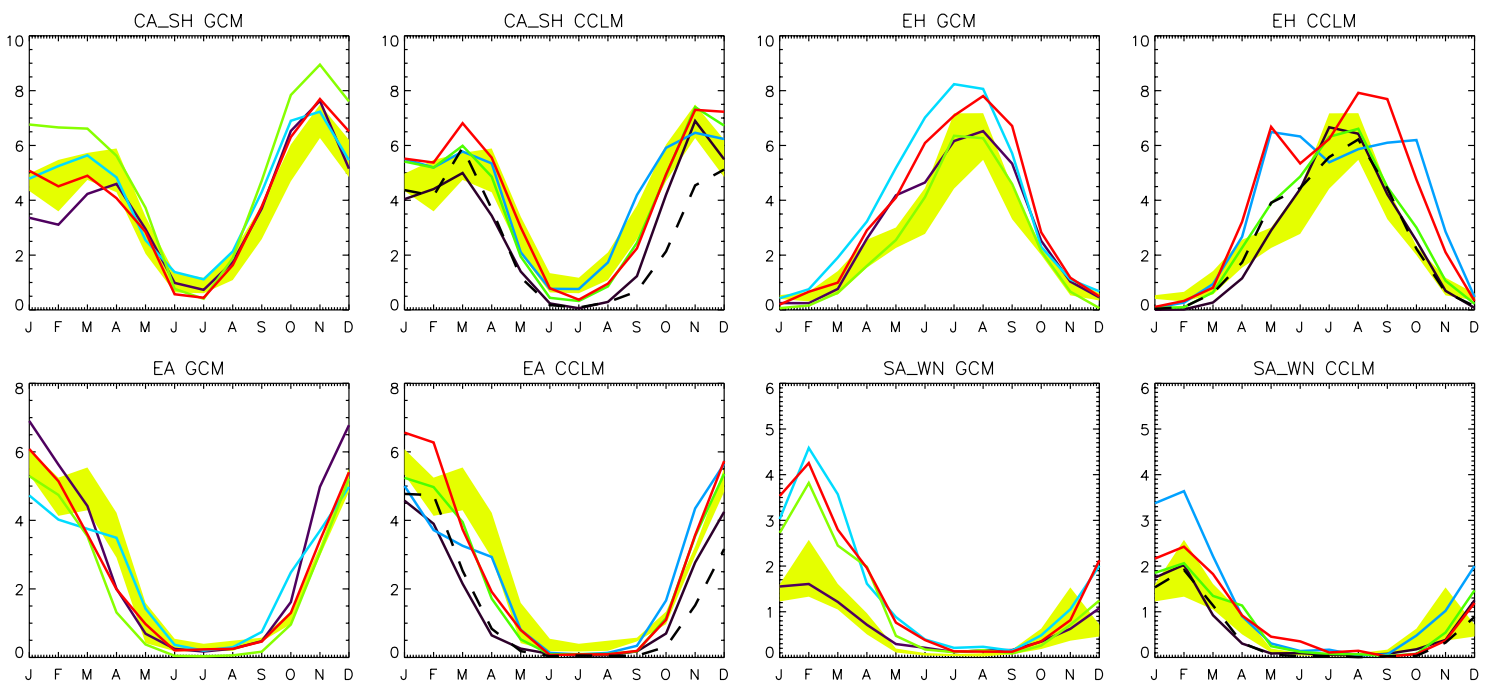

SA_WN GCM

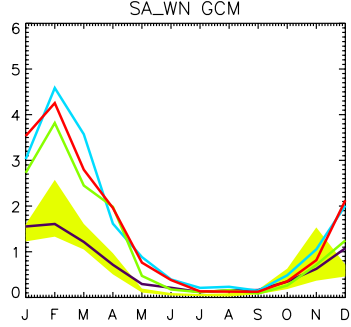

SA_WN CCLM

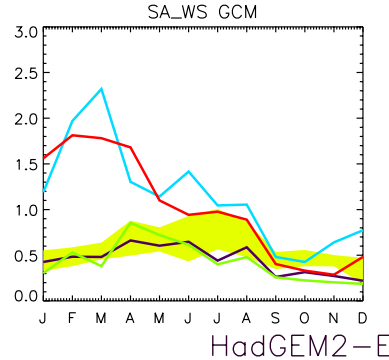

SA_WS CCLM

SA_E GCM

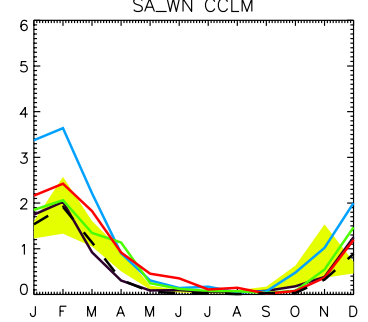

CNRM-CM5
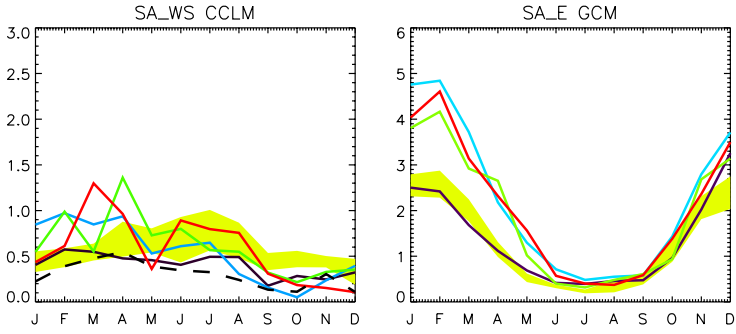

SA_E CCLM

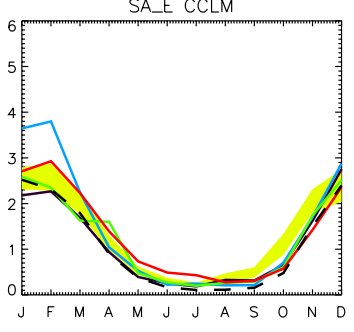

$M P \mid-E S M-L R$

CCLM_CNRM-CM5

EC-EARTH

CCLM_MPI-ESM-LR

CCLM_EC-EARTH

CCLM_ERA

Fig. 7 Annual cycles of mean daily precipitation ( $\mathrm{mm} /$ day) for the GCMs (first and third column) and CCLM (second and fourth column) over the 10 different sub-regions indicated in Fig. 1. The driving GCM and the corresponding downscaled run with CCLM are indicated by the same coloured line. For the CCLM runs, the evaluation run is also shown for comparison (dashed line). The light-green band indicates the range of available observations, listed in Panitz et al. (2014) 

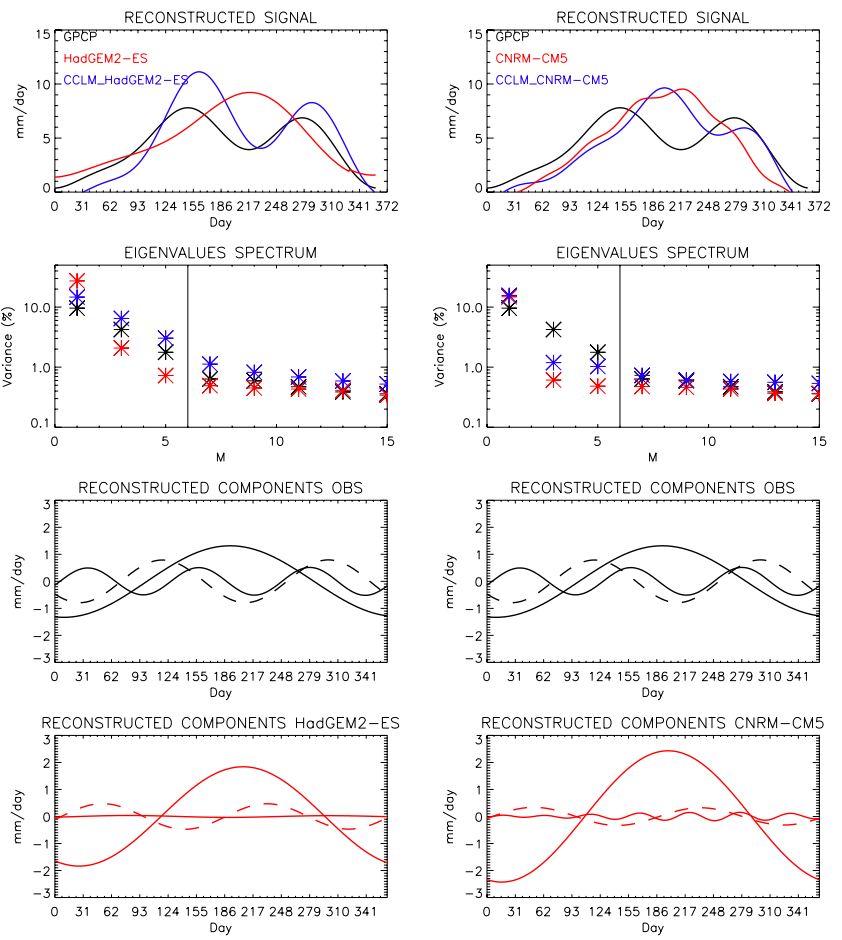

RECONSTRUCTED COMPONENTS CCLM
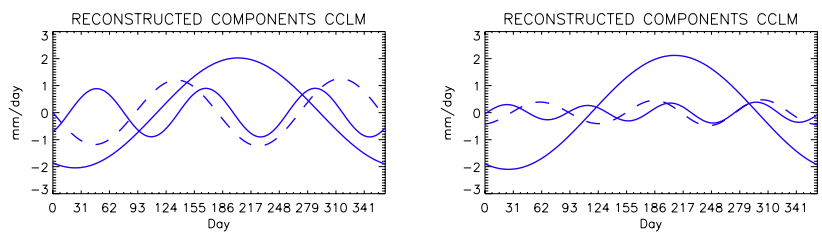

Fig. 8 Singular spectral analysis of the annual cycle of daily precipitation for West-Africa South region, for GPCP (black), the forcing GCM (red) and the corresponding downscaled run with CCLM (blue). First row shows the signal reconstructed by using the first six principal components only (Eq. 4 with $\mathrm{M}=6$ ). Second row shows the eigenvalue spectra, i.e. the percentage of variance explained as a

the reference dataset (black), the GCM (red) and CCLM (blue), respectively.

For the GPCP dataset, used here as reference (results with TRMM are similar and therefore not shown), the singular spectrum becomes flat for $\mathrm{M}>6$ (black crosses in the second row); as a consequence, the precipitation time series can be significantly reconstructed by using only the first six EOFs. The result, shown in the first row of Fig. 8, is indeed very close to the original time series (Fig. 7). The three significant components $(\mathrm{k}=1,3,5)$, (third row) correspond to a 12, 6 and 4-month oscillation, respectively.

For the GCMs (red lines and crosses), the singular spectrum becomes flat for $\mathrm{M}>4(\mathrm{M}>2$ for CNRM-CM5) and the first eigenvalue is predominant. The intensity of the first (annual) RC is therefore generally overestimated, whereas both the semiannual and 4-month oscillations are much weaker than for GPCP (compare, for each column, the fourth and third row): as a consequence, the reconstructed
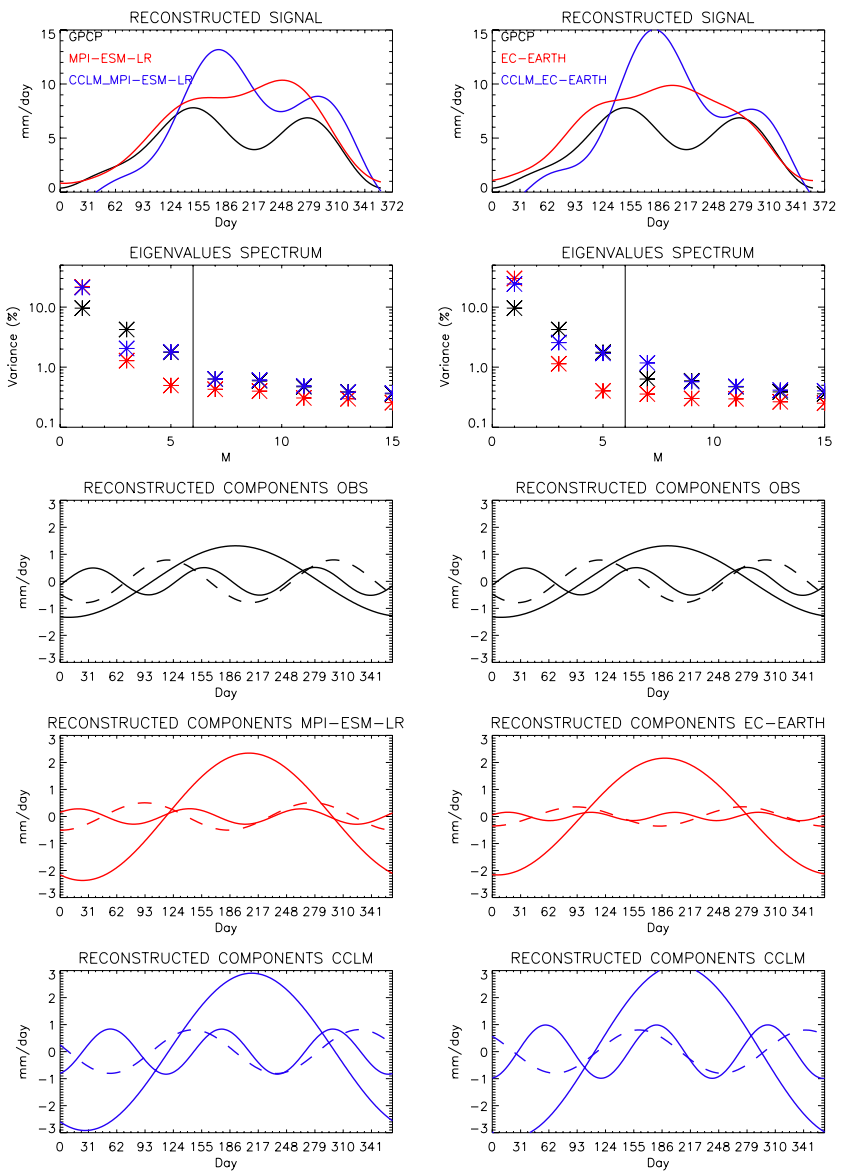

function of M. Here, only odd values are shown, as the singular values for sinusoidal signals appear as pairs of nearly the same value (Rangarajan 1994). The last three rows show the reconstructed components relative to the first three odd eigenvalues (Eq. 3 with $\mathrm{k}=1$, continuous line; $\mathrm{k}=3$, dashed line $; \mathrm{k}=5$, dashed-dotted line) for GPCP (black), GCM (red) and CCLM (blue), respectively

signal shows only a unimodal structure, with no sign of the peaks in June and October.

The annual RC of CCLM is generally close to that of the driving GCM (compare the last with the fourth row); this is expected as large-scale features are directly related to the driving boundary conditions. However, the higher frequency components are closer to the observed ones, especially the 4-month one. As a result, the reconstructed signal (first row) is closer to GPCP than the GCM ones, especially for CCLM-HadGEM2-ES where both the intensity and the phase are reproduced satisfactorily. In cases of CCLM-ECEarth and CCLM-MPI-ESM-LR the strong overestimation of the precipitation intensity seems to be related to the overestimation of the annual component, similar to that of the driving GCM, as shown by the corresponding values of the first components of the singular spectrum.

Summarizing, SSA shows that the precipitation time series simulated by CCLM in WA_S can be separated in 

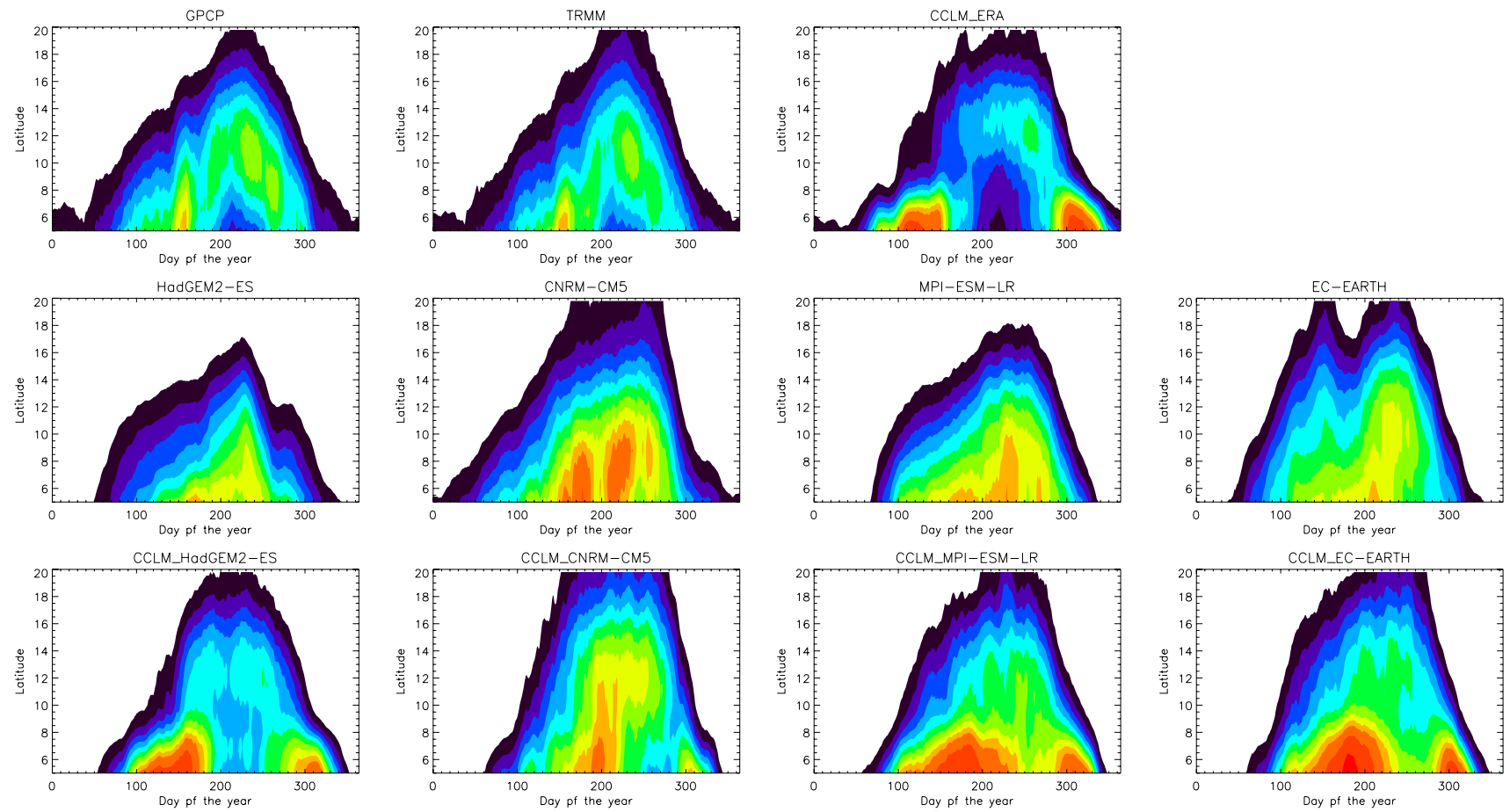

Prec. $(\mathrm{mm} / \mathrm{day})$

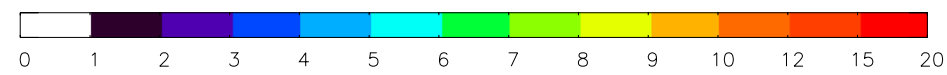

Fig. 9 Hovmöller diagram of mean annual cycle of precipitation (mm/day) over West Africa (averaged over the region $\left.10^{\circ} \mathrm{W}-10^{\circ} \mathrm{E}\right)$. A 20 -day moving average has been used to remove high-frequency variability

three main components; the first one, the annual oscillation, is directly inherited from the driving GCM and affects the intensity of the resulting signal; the second component (semiannual) is somehow reproduced by the GCMs but generally underestimated, whereas CCLM results are closer to GPCP; the third component (4-month) is not present in any of the GCMs results and only CCLM is able to realistically reproduce this high frequency oscillation, and, as a consequence, the bimodal distribution of the observed precipitation.

\subsection{WAM climatology}

Figure 9 shows Hovmöller diagrams of mean annual cycle of precipitation over West Africa (averaged over the region $\left.10^{\circ} \mathrm{W}-10^{\circ} \mathrm{E}\right)$. As discussed by e.g., Nikulin et al. (2012) it is challenging for both GCMs and RCMs to simulate the complexity of processes responsible for the WAM. When driven by ERA-interim most RCMs are able to capture the two main precipitation peaks, but their position and intensity differ greatly across the models (Nikulin et al. 2012; Gbobaniyi et al. 2013). CCLM is somehow able to reproduce the peaks over the Guinea Gulf $\left(5^{\circ} \mathrm{N}-7^{\circ} \mathrm{N}\right)$ in May and the Sahel $\left(10^{\circ} \mathrm{N}-12^{\circ} \mathrm{N}\right)$ in September, respectively, although the first one is overestimated and the second one underestimated (Panitz et al. 2014). On the contrary, none of the GCMs is able to reproduce correctly the WAM seasonal characteristics, with HadGEM-2-ES, EC-Earth, and MPI-ESM-LR underestimating the first peak and CNRMCM5 largely overestimating it. As discussed by Laprise et al. (2013) this may be due to the low spatial resolution of the GCMs' grid, so that the peak is probably an extension of the ocean precipitation, in addition to the misrepresentation of the seasonal cycle of the SST in the Atlantic Ocean. The second peak is reproduced satisfactorily only by ECEarth, but all GMCs misrepresent the Monsoon jump, i.e., the abrupt latitudinal shift of precipitation around June.

CCLM results are heterogeneous, as the influence of the driving GCM is added to the RCM's own deficiencies. For instance, the first peak is usually largely overestimated, as a result of CCLM overestimating precipitation over the sea in the Guinea region (compare Fig. 6). However, some improvement compared to the GCMs is visible, such as the latitudinal extension of the monsoon rainbelt for CCLMHadGEM2-ES, and the intensity and position of the summer peak over the Sahel for CCLM-CNRM-CM5. For the other GCMs, it is hard to discern a significant improvement of the WAM climatology. As stated by Laprise et al. (2013), if driven by incorrect boundary conditions, there is a limit to what RCMs are able to correct. 

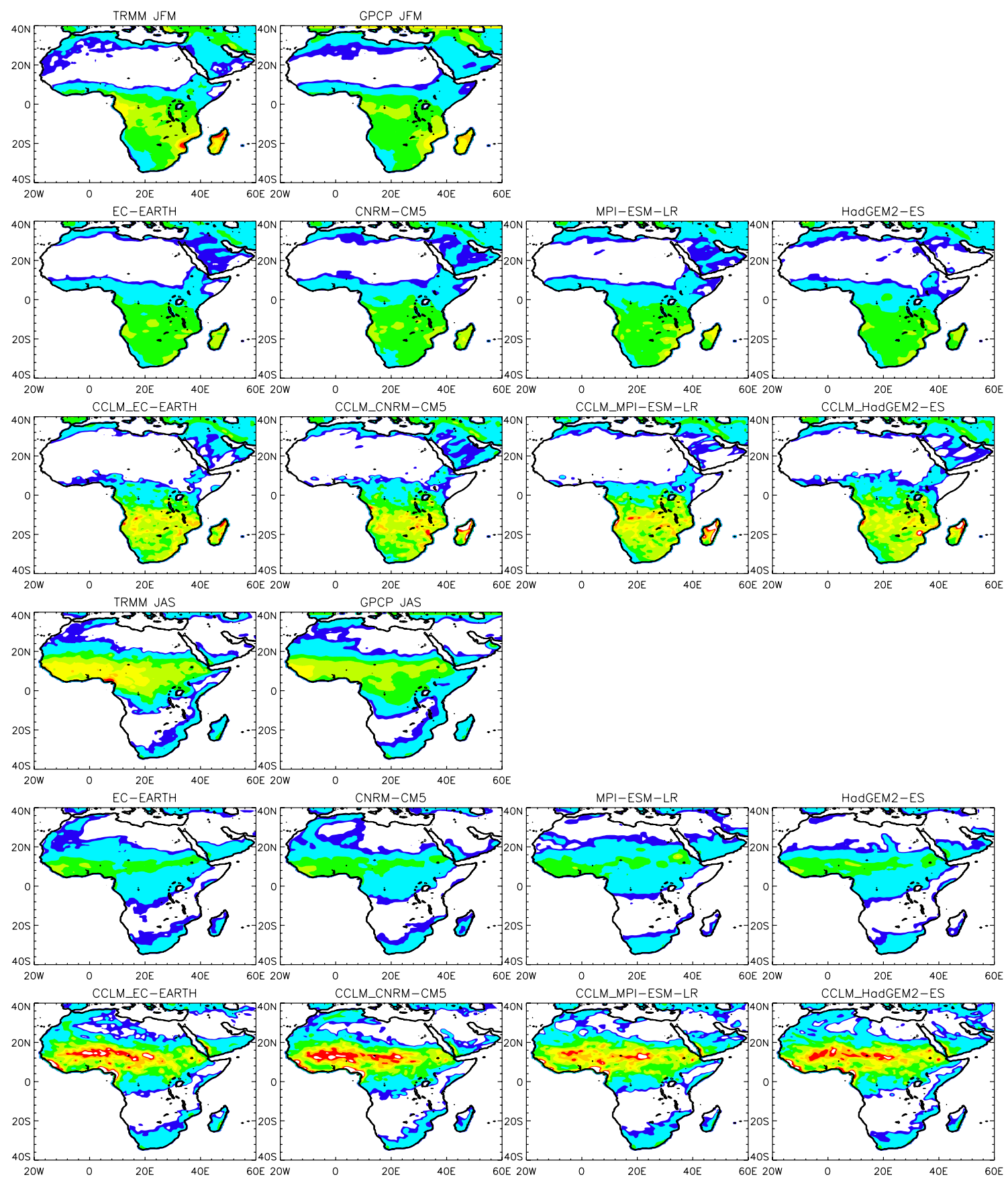

$\operatorname{STDDEV}(\mathrm{mm} / \mathrm{day})$

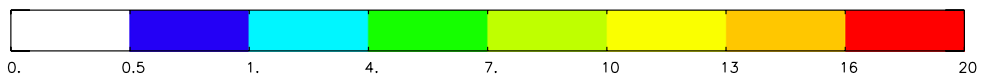

Fig. 10 Standard deviation of daily precipitation ( $\mathrm{mm} /$ day) for the GCMs and CCLM, for austral and boreal summer (top three and bottom three rows, respectively). GPCP and TRMM values are shown for comparison

3.5 Variability and probability distribution function of daily precipitation

From the analysis so far we found that CCLM is able to reproduce the general African climatology (with results comparable to GCMs and other RCMs) but determining whether the downscaled simulations are consistently improving over the large-scale driving ones is not straightforward. As stated by e.g., Rockel et al. (2008) downscaling is not able to improve the simulation skills of large-scale fields over those simulated by the GCMss, and, according to Di Luca et al. (2012)), in order to add value, regional 
climate statistics have to contain fine scale variability that is absent on a coarser grid.

Following Lee and Hong (2013) we therefore compute the Standard Deviation (SD) of daily precipitation for each individual year, and subsequently time averaged it over the entire period (1989-2005). Results are shown in Fig. 10. CCLM exhibits larger daily variation of precipitation compared to the GCMs, both in JFM and JAS. In particular, in JFM, CCLM's results are similar to the TRMM ones, with values of SD larger than $7 \mathrm{~mm}$ /day over large part of central Africa, and with SD larger than $10 \mathrm{~mm} /$ day over Madagascar, Mozambique and, partially, the coasts of Angola and Gabon. GCMs' values are smaller and generally more homogeneous, somehow closer to the low resolution $\left(1^{\circ}\right)$ GPCP dataset, although a general underestimation over South-East Africa is evident. Compared to both TRMM and GPCP, GCMs clearly underestimate the SD in JAS over all the area affected by the WAM, from the Gulf of Guinea to Ethiopia, whereas CCLM's values are closer to the observed ones, although partially overestimated over the Sahel. According to Feser et al. (2011) the added variability occurs mainly on spatial scales that are best resolved by the regional model. Our results are also in agreement with those of Lee and Hong (2013), who compared GCM's results to those of an RCM at two different resolution, showing that the precipitation variance increase with the model resolution.

Figure 11 shows the PDF of daily precipitation for the CORDEX evaluation regions, for the GCMs and the downscaled CCLM runs. It is evident that the CCLM's results outperform those of the driving GCMs over all areas for small to moderate (up to $20 \mathrm{~mm} /$ day) precipitation amounts. A slight overestimation persists up to $5 \mathrm{~mm} /$ day over WA_S and CA_SH, similar to the driving GCMs, but in general the shape of the distribution is closer to the observed one than the GCMs' ones. For larger precipitation amounts, the uncertainty in the observations becomes relevant. Generally CCLM's results are closer to the high resolution TRMM, whereas the GCMs are more similar to GPCP. Our results are in line to those of Crétat et al. (2013) who, by comparing two RCM simulations at different spatial resolutions over Africa, found that the higher resolution simulation generally shows a greater number of the highest intensity events, toward the right tail of the distribution.

\subsection{Impact-relevant precipitation indices}

Impact models, such as hydrological and crop models, are affected not only by the mean spatial and temporal precipitation characteristics, but also by extreme events and higher order statistics. Therefore, here we evaluate the ability of CCLM to reproduce three impact-relevant indices, namely the number of consecutive wet (i.e., daily precipitation
$>1 \mathrm{~mm}$ ) and dry days, and the number of intense precipitation events (i.e., number of rainy days when precipitation exceeds the 95th percentile). As extreme events are characterized by high spatial and temporal variability, especially at small/local scales, it is very challenging for climate models to correctly reproduce them (Crétat et al. 2013; Lee and Hong 2013).

Figure 12 shows the observed and modelled seasonal maximum number of consecutive wet days (CWD). Generally, all GCMs tend to overestimate CWD, especially over central Africa in JFM and the Guinea Gulf in JAS, with values as high as four times the observed ones. CCLM results are much closer to the observations, especially to GPCP, although in summer CWD is still slightly overestimated over the area between $0^{\circ} \mathrm{N}$ and $15^{\circ} \mathrm{N}$. It is interesting to note that the downscaled CCLM simulations are similar to the ERA-Interim driven run, especially over land, and seem to be somehow independent of the influence of the driving GCM (i.e., lateral boundary conditions) compared to, for instance, the precipitation mean intensity. This suggests that, although lateral boundary condition greatly affect the RCMs' skills in simulating the general features of the African climate, RCMs are clearly more able to reproduce small scale, high variable processes and, in turn, higher order precipitation statistics.

Maximum number of consecutive dry days (CDD) is shown in Fig. 13. GCMs' results are quantitatively similar to observed values, especially over land, although in JFM CNRM-CM5 and EC-Earth underestimate CDD over South Africa, whereas in JAS over North-East Africa CDD is overestimated by HadGEM2-ES and MPI-ESMLR and underestimated by CNRM-CM5 and EC-Earth. Over these areas and seasons, CCLM results are generally closer to the observations, but some discrepancies remain especially over north-equatorial Africa in JFM, where the length of the dry spells is generally overestimated. In JAS, the effect of lateral boundary conditions is evident by analyzing the geographical extension of the areas of very short dry spells (CDD $<10$, white band centered along $10^{\circ} \mathrm{N}$ in the figure), which, in each downscaled run, is very similar to that of the corresponding GCM, and in general, larger than the ERA-Interim driven run. In particular, CDD is too low along the Guinea coast, and too high over the eastern coast and the Horn of Africa, although large discrepancies exist in that region amongst the observational datasets.

Finally, the mean number of intense precipitation events i.e., number of rainy days (i.e., with precipitation $>1 \mathrm{~mm}$ ) when precipitation exceeds the 95th percentile, is shown in Fig. 14. In a recent work, Crétat et al. (2013) assess, for the first time, the ability of climate models to capture the mean spatial and temporal characteristics of daily intense rainfall events over (continental) Africa. They compare 

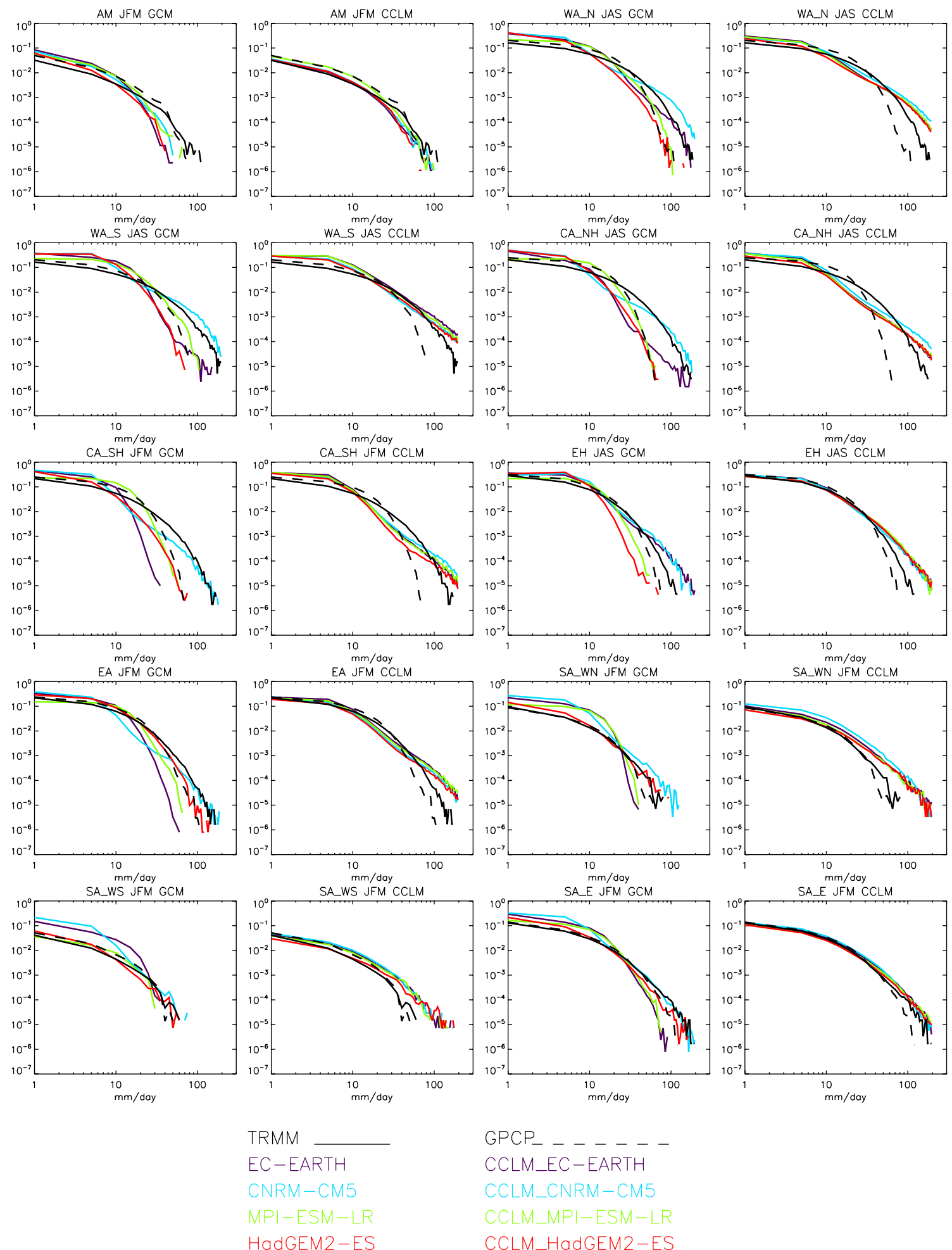

GPCP

CCLM EC-EARTH

CCLM_CNRM-CM5

$C C L M+M P I-E S M-L R$

HadGEM2-ES

Fig. 11 Probability distribution functions of seasonal daily precipitation (mm/day) for the GCMs (first and third column) and CCLM (second and fourth column) over the 10 different sub-regions. Note that the selected season is dependent on the region. The driving GCM

and the corresponding downscaled run with CCLM are indicated by the same coloured line. Two observational datasets (TRMM and GPCP) are also reported for comparison 

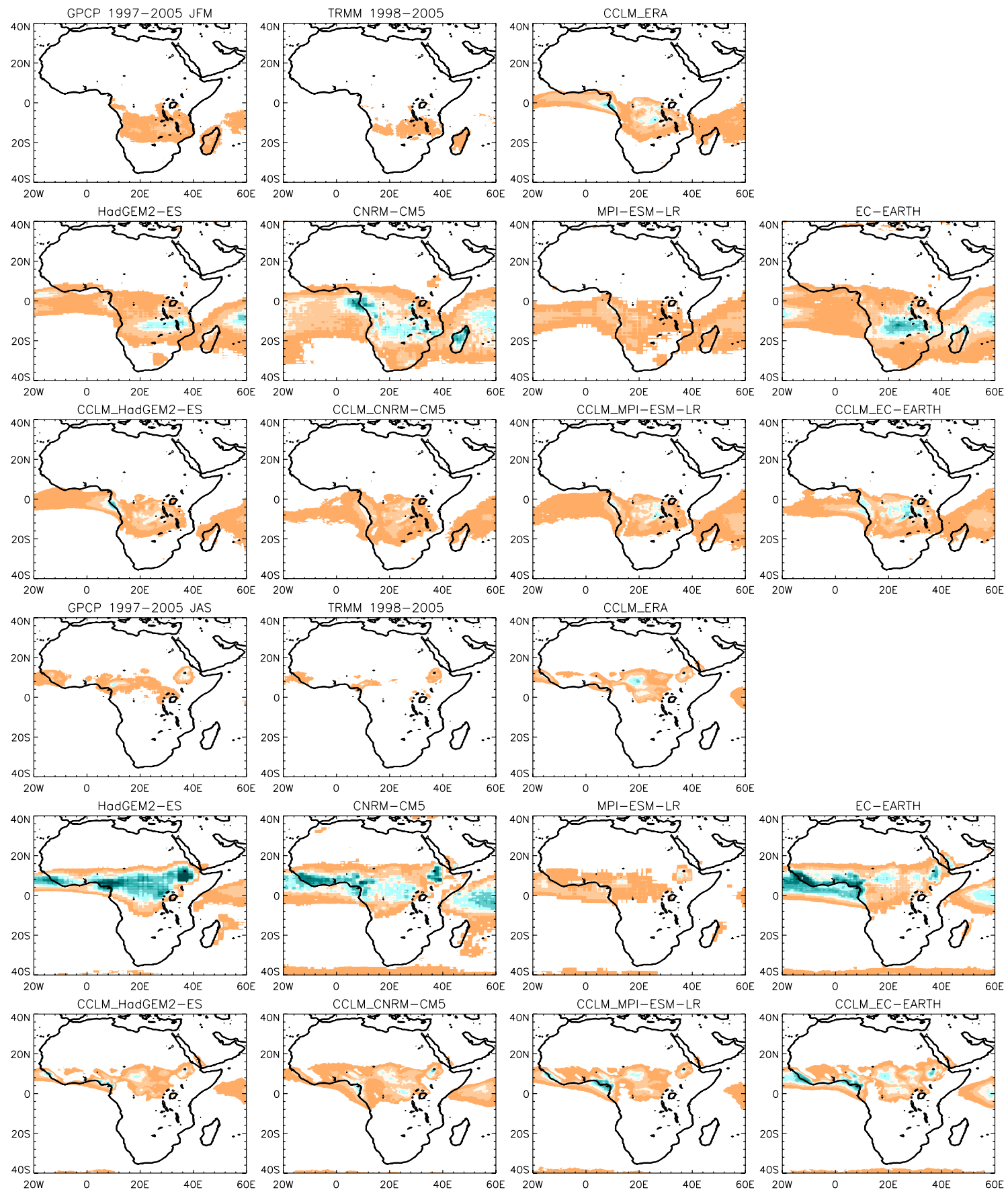

CWD

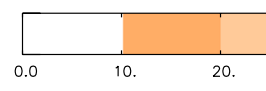

Fig. 12 Maximum number of consecutive wet days (i.e., precipitation $>1 \mathrm{~mm} /$ day) (CWD) for the GCMs and CCLM, for austral and boreal summer (top three and bottom three rows, respectively). GPCP and TRMM observations are shown for comparison. In addition, the evaluation run (i.e CCLM forced by ERA-Interim) is shown

largely overestimate the frequency of intense rain events, both in JFM, over central Africa, and in JAS, over the entire monsoon belt. CCLM results are closer to the observations (especially to GPCP) both in boreal and austral 

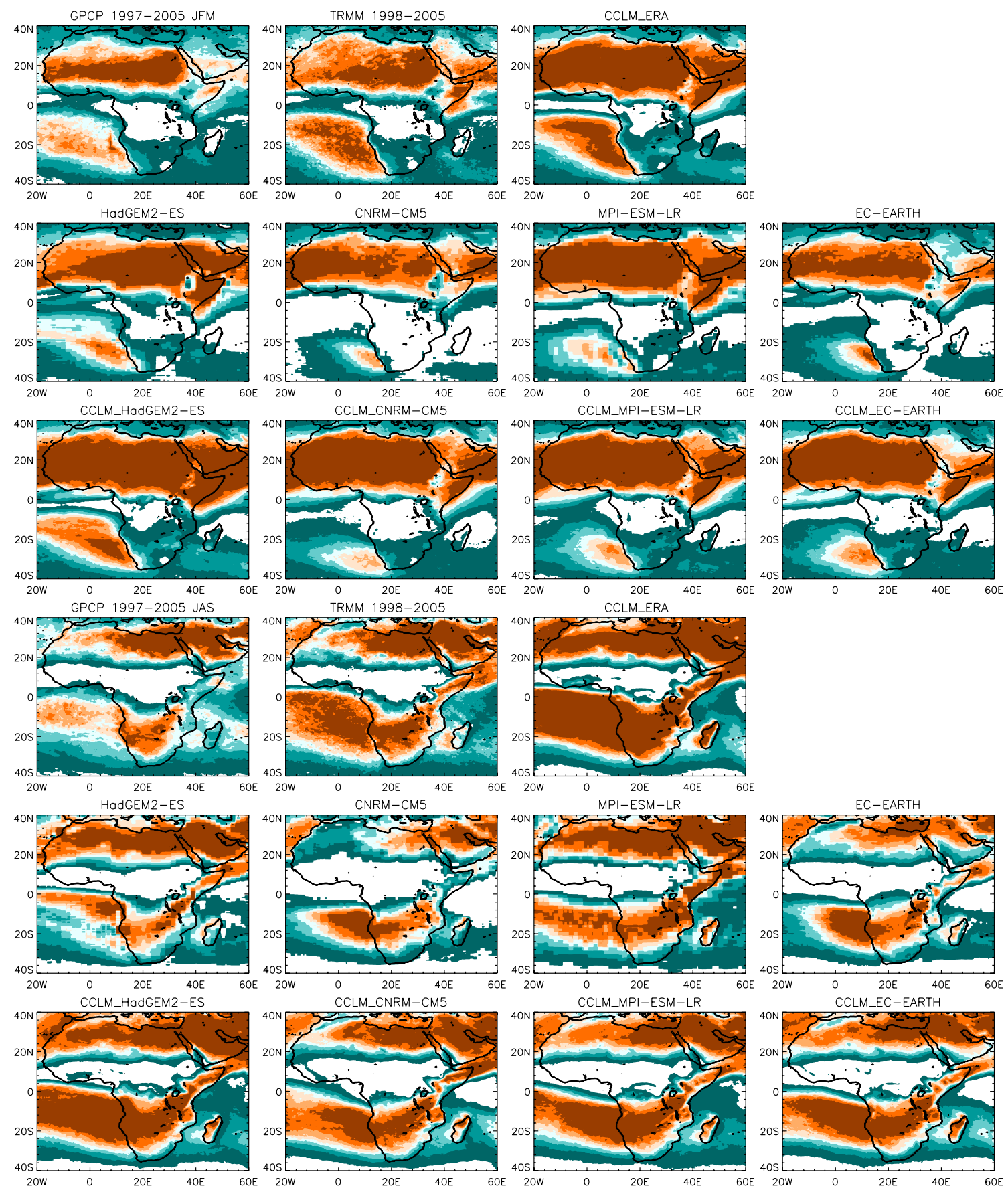

CDD

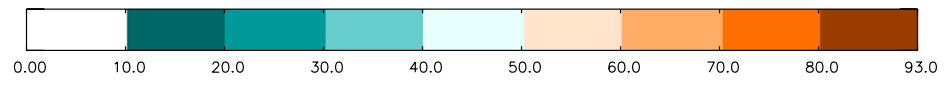

Fig. 13 Maximum number of consecutive dry days (i.e., precipitation $<1 \mathrm{~mm} /$ day) (CDD) for the GCMs and CCLM, for austral and boreal summer (top three and bottom three rows, respectively). GPCP and TRMM observations are shown for comparison. In addition, the evaluation run (i.e CCLM forced by ERA-Interim) is shown

to erroneous, or at least oversimplified assumptions in the convection schemes. Although this may be true and despite climate models still cannot realistically simulate daily intense rainfall events with high accuracy, it is nevertheless summer, although the frequency of intense events is still overestimated over the Congo basin in JFM and the areas around Central African Republic and South Sudan in JAS. Crétat et al. (2013) claim that this behaviour may be due 

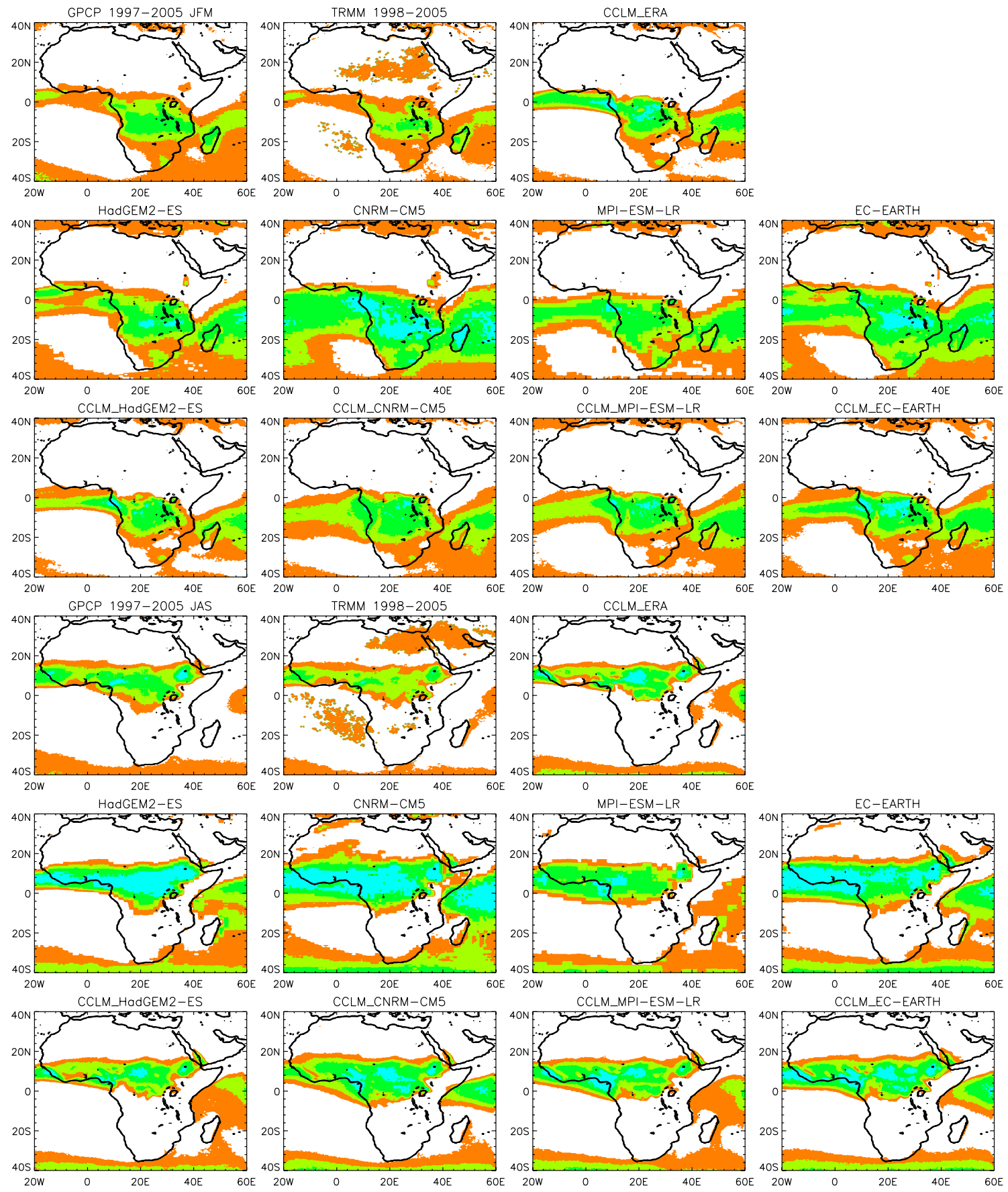

Events/seaon

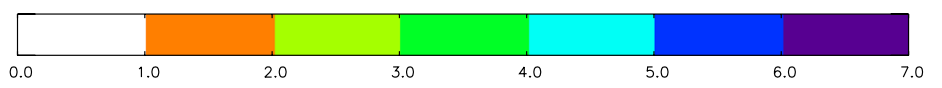

Fig. 14 Mean number of intense precipitation events (i.e., the number of rainy days with precipitation $\geq 95$ th percentile) for the GCMs and CCLM, for austral and boreal summer (top three and bottom three rows, respectively). GPCP and TRMM observations are shown for comparison. In addition, the evaluation run (i.e CCLM forced by ERA-Interim) is shown encouraging that RCM downscaled simulations greatly improve GCM results especially for those characteristics that may be more relevant to impact and adaptation communities.

\section{Summary and concluding remarks}

We presented the results of the application of the COSMOCLM regional climate model over the CORDEX-Africa 
domain. This study builds on the previous work by Panitz et al. (2014) where the CCLM model driven by ERAInterim was thoroughly evaluated, and it lays the basis for an upcoming study where the climate change simulations will be analyzed.

Here it was important first to generally evaluate the ability of CCLM to reproduce the general characteristics of the African climate (e.g., seasonal distribution of temperature and precipitation, and WAM climatology) and, second, to investigate whether the downscaled simulations add value to those of the driving GCMs. In addition, whereas previous works usually showed RCM results either forced by only one GCM or evaluated against only one observational dataset, our study involving 4 driving GCMs and several observational datasets clearly represents a step forward in a comprehensive and thorough analysis of the performances of the RCM.

It is found that, in general, the geographical distribution of mean sea level pressure, surface temperature and seasonal precipitation is strongly affected by the boundary conditions (i.e. driving GCM): for instance, GCMs show a marked cold bias, especially in JFM, which CCLM is only partially able to correct, especially in areas such as Central and South Africa where the evaluation runs showed a slight warm bias. In the region along the Guinea Gulf and over the Sahel, regions where the temperature in the ERA-interim driven simulation was already colder than the observed one, the cold bias inherited by the GCMs in JAS is generally worsened.

Concerning precipitation, the influence of the lateral boundary condition is evident especially in JFM as most of the GCMs misplace the position of the monsoonal rain belt. As expected, the geographical distribution of seasonal precipitation as simulated by CCLM follows closely the one inherited by the GCMs. Precipitation intensity over land is therefore not always better reproduced by the RCM, which shows a general dry bias, consistent to the 'structural' bias of the evaluation run driven by ERA-Interim. However, some improvement is evident, e.g. over South Africa in JFM, where the GCMs' wet bias is corrected. In the WAM area it is difficult to discern a homogeneous and consistent improvement of the RCM simulations over the driving GCMs. However, by performing a SSA over the regions along the Gulf of Guinea it was shown that CCLM is able to better represent the subannual principal components of the precipitation time series, in turn reproducing satisfactorily the bimodal distribution of the annual cycle, whereas GCMs are not able to simulate this feature and they show a unimodal distribution.

The inability of RCMs to significantly improve (seasonal) mean climatology is somehow expected, as, in order to add value, regional climate statistics have to contain fine scale variability that would be absent on a coarser grid (Feser et al. 2011).
This may lead to the question of how much a RCM can be trusted in the representation of the extreme climate if the mean feature of the climate are not better (and in some case even worse) than a GCM? We believe that the fact that CCLM may not add significant value to the representation of the general climatology over Africa depends on several factors, including the biases inherited by the driving GCM (e.g., the misrepresentation of the monsoon rainbelt in JFM), structural biases of the RCM (e.g., the dry bias over land, which may be related to soil parameterization), and, last but not least, the choice of the observational dataset (e.g. CCLM scores better when compared to TRMM rather than GPCP). However, by analyzing the Standard Deviation and probability distribution function of daily precipitation, we have shown that CCLM's results are clearly closer to observations (especially high-resolution ones, such as TRMM) than the GCMs' ones, and both tails of the PDF are better reproduced by CCLM over all the evaluation areas. Furthermore, it was shown that CCLM is able to better simulate some precipitation indices such as the number of consecutive wet and dry days, and the frequency of heavy rain event: these are indeed the areas where added value is expected to be found, and, therefore, supposedly most reliable when looking at climate change projections. Although some issue remain open to further research such as, for instance, the parameterization of convective precipitation, which may play a relevant role especially in tropical regions, we demonstrated that RCMs are useful tools for the generation of climate change projections, especially for those characteristics that may be more relevant to impact and adaptation communities.

Acknowledgments We acknowledge the World Climate Research Programme's Working Group on Coupled Modelling, which is responsible for CMIP, and we thank the climate modeling groups for producing and making available their model output. For CMIP the U.S. Department of Energy's Program for Climate Model Diagnosis and Intercomparison provides coordinating support and led development of software infrastructure in partnership with the Global Organization for Earth System Science Portals. Computational resources were made available by the German Climate Computing Centre (DKRZ) through support from the German Federal Ministry of Education and Research (BMBF).

Open Access This article is distributed under the terms of the Creative Commons Attribution License which permits any use, distribution, and reproduction in any medium, provided the original author(s) and the source are credited.

\section{References}

Abiodun BJ, Pal JS, Gutowski WJ, Adedoyin A (2008) Simulation of West African monsoon using RegCM3 Part II: impacts of deforestation and desertification. Theor Appl Climatol 93(3-4):245261. doi:10.1007/s00704-007-0333-1 
Adler R, Huffman G, Chang A, Ferraro R, Xie P, Janowiak J, Rudolf B, Schneider U, Curtis S, Bolvin D, Gruber A, Susskind J, Arkin P, Elkin E (2003) The version 2 global precipitation climatology project (GPCP) monthly precipitation analysis (1979-present). J Hydrometeorol 4:1147-1167

Afiesimama Ea, Pal JS, Abiodun BJ, Gutowski WJ, Adedoyin A (2006) Simulation of West African monsoon using the RegCM3. Part I: model validation and interannual variability. Theor Appl Climatol 86(1-4):23-37. doi:10.1007/s00704-005-0202-8

Brands S, Herrera S, Fernández J, Gutiérrez JM (2013) How well do CMIP5 earth system models simulate present climate conditions in Europe and Africa? Clim Dynam 41(3-4):803-817. doi:10.1007/s00382-013-1742-8

Castro CL, Pielke R Sr, Leoncini G (2005) Dynamical downscaling: assessment of value retained and added using the regional atmospheric modeling system (RAMS). J Geophys Res 110(D5):1-21. doi: $10.1029 / 2004 J D 004721$

Cook K (1999) Generation of the African easterly jet and its role in determining West African precipitation. J Clim 12:1165-1184

Crétat J, Vizy EK, Cook KH (2013) How well are daily intense rainfall events captured by current climate models over Africa? Clim Dynam 42:2691. doi:10.1007/s00382-013-1796-7

Davies HC (1976) A laterul boundary formulation for multi-level prediction models. Q J R Meteorol Soc 102(432):405-418. doi:10.1 002/qj.49710243210

Davies H (1983) Limitations of some common lateral boundary schemes used in regional NWP models. Mon Weather Rev 111:1002-1012. doi:10.1175/1520-0493(1983)111<1002:LOSC $\mathrm{LB}>2.0 . \mathrm{CO} ; 2$

Di Luca A, Elía R, Laprise R (2012) Potential for small scale added value of RCMs downscaled climate change signal. Clim Dynam 40(3-4):601-618. doi:10.1007/s00382-012-1415-Z

Diaconescu EP, Laprise R (2013) Can added value be expected in RCM-simulated large scales? Clim Dynam 41:1769-1800. doi:10.1007/s00382-012-1649-9

Diallo I, Sylla MB, Giorgi F, Gaye AT, Camara M (2012) Multimodel GCM-RCM ensemble-based projections of temperature and precipitation over West Africa for the Early 21st century. Int J Geophys 2012:1-19. doi:10.1155/2012/972896

Doms G (2011) A description of the nonhydrostatic regional COSMO model part 1: dynamics and numerics. DWD, Offenbach, Germany, http://www.cosmo-model.org/content/model/ documentation/core/default.htm

Dosio A, Paruolo P (2011) Bias correction of the ENSEMBLES highresolution climate change projections for use by impact models: evaluation on the present climate. J Geophys Res 116(D16):1-22. doi:10.1029/2011JD015934

Druyan LM, Feng J, Cook KH, Xue Y, Fulakeza M, Hagos SM, Konaré A, Moufouma-Okia W, Rowell DP, Vizy EK, Ibrah SS (2010) The WAMME regional model intercomparison study. Clim Dynam 35(1):175-192. doi:10.1007/s00382-009-0676-7

Endris HS, Omondi P, Jain S, Lennard C, Hewitson B, Chang'a L, Awange JL, Dosio A, Ketiem P, Nikulin G, Panitz HJ, Büchner M, Stordal F, Tazalika L (2013) Assessment of the performance of CORDEX regional climate models in simulating east African rainfall. J Clim 26(21):8453-8475. doi:10.1175/JCLI-D-12-00708.1

Feser F, Rockel B, von Storch H, Winterfeldt J, Zahn M (2011) Regional climate models add value to global model data: a review and selected examples. Bull Am Meteorol Soc 92(9):1181-1192

Gbobaniyi E, Sarr A, Sylla MB, Diallo I, Lennard C, Dosio A, Dhiédiou A, Kamga A, Klutse NAB, Hewitson B, Nikulin G, Lamptey B (2014) Climatology, annual cycle and interannual variability of precipitation and temperature in CORDEX simulations over West Africa. Int J Climatol 34:2241-2257. doi:10.1002/joc.3834
Giorgi F, Jones C, Asrar G (2009) Addressing climate information needs at the regional level: the CORDEX framework. World Meteorol Organ (WMO) Bull 58(July):175-183

Hassani H (2007) Singular spectrum analysis: methodology and comparison. J Data Sci 5:239-257

Heise E, Lange M, Ritter B, Schrodin R (2003) Improvement and validation of the multilayer soil model. COSMO Newsl 3:198-203

Hong SY, Kanamitsu M (2014) Dynamical downscaling: fundamental issues from an NWP point of view and recommendations. Asia Pacific J Atmos Sci 50(1):83-104. doi:10.1007/ s13143-014-0029-2

Huffman GJ, Adler RF, Bolvin DT, Gu G (2009) Improving the global precipitation record: GPCP version 2.1. Geophys Res Lett 36(17):L17,808. doi:10.1029/2009GL040000

IPCC (2007) Climate change 2007: the physical science basis: contribution of Working Group I to the fourth assessment report of the intergovernmental panel on climate change. Cambridge University Press, Cambridge, United Kingdom and New York, NY, USA

Jenkins GS, Gaye AT, Sylla B (2005) Late 20th century attribution of drying trends in the Sahel from the regional climate model (RegCM3). Geophys Res Lett 32(22):L22,705. doi:10.1029/200 5GL024225

Kalognomou EA, Lennard C, Shongwe M, Pinto I, Favre A, Kent M, Hewitson B, Dosio A, Nikulin G, Panitz HJ, Büchner M (2013) A diagnostic evaluation of precipitation in CORDEX models over Southern Africa. J Clim 26(23):9477-9506. doi:10.1175/JCLI-D-12-00703.1

Kim J, Kim TK, Arritt RW, Muller NL (2002) Impacts of increased atmospheric $\mathrm{CO} 2$ on the hydroclimate of theWestern United States. J Clim 15:1926-1942

Kim J, Waliser DE, Mattmann CA, Goodale CE, Hart AF, Zimdars PA, Crichton DJ, Jones C, Nikulin G, Hewitson B, Jack C, Lennard C, Favre A (2013) Evaluation of the CORDEX-Africa multi-RCM hindcast: systematic model errors. Clim Dynam. doi:10.1007/s00382-013-1751-7

Laprise R, Hernández-Díaz L, Tete K, Sushama L, Šeparović L, Martynov A, Winger K, Valin M (2013) Climate projections over CORDEX Africa domain using the fifth-generation Canadian regional climate model (CRCM5). Clim Dynam 41:3219-3246. doi:10.1007/s00382-012-1651-2

Lawrence PJ, Chase TN (2007) Representing a new MODIS consistent land surface in the Community Land Model (CLM 3.0). J Geophys Res 112(G1):G01,023. doi:10.1029/2006JG000168

Lee JW, Hong SY (2013) Potential for added value to downscaled climate extremes over Korea by increased resolution of a regional climate model. Theor Appl Climatol. doi:10.1007/ s00704-013-1034-6

Lee JW, Hong SY, Chang EC, Suh MS, Kang HS (2014) Assessment of future climate change over East Asia due to the RCP scenarios downscaled by GRIMs-RMP. Clim Dynam 42(3-4):733-747. doi:10.1007/s00382-013-1841-6

Legates DR, Willmott CJ (1990) Mean seasonal and spatial variability in gauge-corrected, global precipitation. Int J Climatol 10(2):111-127. doi:10.1002/joc.3370100202

Lott F, Miller MJ (1997) A new subgrid-scale orographic drag parametrization: its formulation and testing. Q J R Meteorol Soc 123(537):101-127. doi:10.1002/qj.49712353704

Mariotti L, Coppola E, Sylla MB, Giorgi F, Piani C (2011) Regional climate model simulation of projected 21 st century climate change over an all-Africa domain: comparison analysis of nested and driving model results. J Geophys Res 116(d15): doi:10.1029 /2010JD015068

Mellor GL, Yamada T (1982) Development of a turbulence closure model for geophysical fluid problems. Rev Geophys 20(4):851875. doi:10.1029/RG020i004p00851 
Mironov D, Raschendorfer M (2001) Evaluation of empirical parameters of the new LM surface-layer parameterization scheme: results from numerical experiments including soil moisture analysis. COSMO technical report 1, DWD, Offenbach, Germany

Mitchell TD, Jones PD (2005) An improved method of constructing a database of monthly climate observations and associated high-resolution grids. Int J Climatol 25(6):693-712. doi:10.1002/joc.1181

Moss RH, Ja Edmonds, Ka Hibbard (2010) The next generation of scenarios for climate change research and assessment. Nature 463(7282):747-756. doi:10.1038/nature08823

Nikulin G, Jones C, Giorgi F, Asrar G, Büchner M, Cerezo-Mota R, Christensen OBs, Déqué M, Fernandez J, Hänsler A, van Meijgaard E, Samuelsson P, Sylla MB, Sushama L (2012) Precipitation climatology in an ensemble of CORDEX-Africa regional climate simulations. J Clim 25(18):6057-6078. doi:10.1175/JCLI-D-11-00375.1

Paeth H, Mannig B (2012) On the added value of regional climate modeling in climate change assessment. Clim Dynam 41(34):1057-1066. doi:10.1007/s00382-012-1517-7

Paeth H, Hall NM, Gaertner MA, Alonso MD, Moumouni S, Polcher J, Ruti PM, Fink AH, Gosset M, Lebel T, Gaye AT, Rowell DP, Moufouma-Okia W, Jacob D, Rockel B, Giorgi F, Rummukainen M (2011) Progress in regional downscaling of west African precipitation. Atmos Sci Lett 12(1):75-82. doi:10.1002/asl.306

Panitz HJ, Dosio A, Büchner M, Lüthi D, Keuler K (2014) COSMO-CLM (CCLM) climate simulations over CORDEXAfrica domain: analysis of the ERA-Interim driven simulations at 0.44 and 0.22 resolution. Clim Dynam. doi:10.1007/ s00382-013-1834-5

Rangarajan G (1994) Singular spectral analysis of homogeneous Indian monsoon (HIM) rainfall. Proc Indian Acad Sci Earth 4:439-448

Raschendorfer M (2001) The new turbulence parameterization of LM. COSMO News1 1:90-98

Redelsperger JL, Thorncroft CD, Diedhiou A, Lebel T, Parker DJ, Polcher J (2006) African monsoon multidisciplinary analysis: an international research project and field campaign. Bull Am Meteorol Soc 87(12):1739-1746. doi:10.1175/BAMS-87-12-1739

Ritter B, Geleyn JF (1992) A comprehensive radiation scheme for numerical weather prediction models with potential applications in climate simulations. Mon Weather Rev 120(2):303-325

Rockel B, Will A, Hense A (2008) The regional climate model COSMO-CLM (CCLM). Meteorologische Zeitschrift 17(4):347348. doi:10.1127/0941-2948/2008/0309

Rudolf B, Becker A, Schneider U, Meyer-christoffer A, Ziese M (2010) The new GPCC full data reanalysis version 5 providing high-quality gridded monthly precipitation data for the global land-surface is public available since December 2010. GPCC Status Report (December):1-7
Ruti PM, Williams JE, Hourdin F, Guichard F, Boone A, Van Velthoven P, Favot F, Musat I, Rummukainen M, Domínguez M, Gaertner MA, Lafore JP, Losada T, Polcher J, Giorgi F, Xue Y, Bouarar I, Law K, Josse B, Barret B, Yang X, Mari C, Traore AK (2011) The West African climate system: a review of the AMMA model inter-comparison initiatives. Atmos Sci Lett 12(1):116122. doi:10.1002/asl.305

Schrodin R, Heise E (2001) The multi-layer version of the DWD soil model TERRA-LM. COSMO technical report 2, DWD, Offenbach, Germany

Schrodin R, Heise E (2002) A new multi-layer soil-model. COSMO Newsl 2:139-151

Schulz JP (2008) Introducing sub-grid scale orographic effects in the COSMO model. COSMO News1 9:29-36

Seifert A, Beheng KD (2001) A double-moment parameterization for simulating autoconversion, accretion and selfcollection. Atmos Res 59-60:265-281

Steiner AL, Pal JS, Bell JL, Diffenbaugh NS, Boone A, Sloan LC, Giorgi F (2009) Land surface coupling in regional climate simulations of the West African monsoon. Clim Dynam 33(6):869892. doi:10.1007/s00382-009-0543-6

Sylla MB, Giorgi F, Coppola E, Mariotti L (2012) Uncertainties in daily rainfall over Africa: assessment of gridded observation products and evaluation of a regional climate model simulation. Int J Climatol 33(7):n/a-n/a. doi:10.1002/joc.3551

Taylor KE, Stouffer RJ, Meehl GA (2012) An overview of CMIP5 and the experiment design. Bull Am Meteorol Soc 93(4):485498. doi:10.1175/BAMS-D-11-00094.1

Tiedtke M (1989) A comprehensive mass flux scheme for cumulus parameterization in large-scale models. Mon Weather Rev 117(8): 1779-1800

Vuuren DP, Edmonds J, Kainuma M, Riahi K, Thomson A, Hibbard K, Hurtt GC, Kram T, Krey V, Lamarque JF, Masui T, Meinshausen M, Nakicenovic N, Smith SJ, Rose SK (2011) The representative concentration pathways: an overview. Clim Chang 109(1-2):5-31. doi:10.1007/s10584-011-0148-Z

Wang Y, Leung L, McGREGOR J, Lee D (2004) Regional climate modeling: progress, challenges, and prospects. J Meteorol Soc Jpn 82(6): $1599-1628$

Wicker LJ, Skamarock WC (2002) Time-splitting methods for elastic models using forward time schemes. Mon Weather Rev 130(8):2088 2097. doi:10.1175/1520-0493(2002)130<2088:TSM>2.0.CO;2

Xue Y, Sales F, Lau WKM, Boone A, Feng J, Dirmeyer P, Guo Z, Kim KM, Kitoh A, Kumar V, Poccard-Leclercq I, Mahowald N, Moufouma-Okia W, Pegion P, Rowell DP, Schemm J, Schubert SD, Sealy A, Thiaw WM, Vintzileos A, Williams SF, Wu MLC (2010) Intercomparison and analyses of the climatology of the West African Monsoon in the West African monsoon modeling and evaluation project (WAMME) first model intercomparison experiment. Clim Dynam 35(1):3-27. doi:10.1007/s00382-010-0778-2 